Review

\title{
Synthesis and Self-Assembly of Conjugated Block Copolymers
}

\author{
Lin-Lin Xiao ${ }^{1}$, Xu Zhou ${ }^{1}$, Kan Yue ${ }^{1,2}$ and Zi-Hao Guo ${ }^{1,2, *(D)}$ \\ 1 School of Molecular Science and Engineering, South China Advanced Institute for Soft Matter Science \\ and Technology, South China University of Technology, Guangzhou 510640, China; \\ 201920155214@mail.scut.edu.cn (L.-L.X.); zhouxupku@126.com (X.Z.); kanyue@scut.edu.cn (K.Y.) \\ 2 Guangdong Provincial Key Laboratory of Functional and Intelligent Hybrid Materials and Devices, \\ South China University of Technology, Guangzhou 510640, China \\ * Correspondence: guozihao@scut.edu.cn
}

Citation: Xiao, L.-L.; Zhou, X.; Yue, K.; Guo, Z.-H. Synthesis and Self-Assembly of Conjugated Block Copolymers. Polymers 2021, 13, 110 https: / / doi.org/10.3390/ polym 13010110

Received: 4 December 2020 Accepted: 25 December 2020 Published: 29 December 2020

Publisher's Note: MDPI stays neutral with regard to jurisdictional clai$\mathrm{ms}$ in published maps and institutional affiliations.

Copyright: $\odot 2020$ by the authors. Licensee MDPI, Basel, Switzerland. This article is an open access article distributed under the terms and conditions of the Creative Commons Attribution (CC BY) license (https:// creativecommons.org/licenses/by/ $4.0 /)$.

\begin{abstract}
In the past two decades, conjugated polymers (CPs) have drawn great attention due to their excellent conductivity and charge mobility, rendering them broad applications in organic electronics. Controlling over the morphologies and nanostructures of CPs is very important to improve the performance of CP-based devices, which is still a tremendously difficult task. Conjugated block copolymers (cBCPs), composed of different CP blocks or CP coupled with coiled polymeric blocks, not only maintain the advantages of high conductivity and mobility but also demonstrate features of morphological versatility and tunability. Due to the strong $\pi-\pi$ interaction and crystallinity of the conjugated backbones, the self-assembly behaviors of cBCPs are very complicated and largely remain to be explored. In this tutorial review, we first summarize the general synthetic methods for different types of cBCPs. Then, recent studies on the self-assembly behaviors of cBCPs are discussed, with an emphasis on the structural factors that affect the morphologies of cBCPs both in bulk and thin film states. Finally, we briefly provide our outlook on the future research of the self-assembly of cBCPs.
\end{abstract}

Keywords: conjugated block copolymers; block copolymers; self-assembly; microphase separation

\section{Introduction}

Conjugated polymers (CPs) have alternating single and double bonds in the polymer backbone, making the polymer chain rigid and conductive. In 2000, the Noble Prize in Chemistry was awarded to MacDiarmid, Heeger, and Shirakawa in recognition of their discovery of highly conductive polyacetylene [1]. Despite relatively low charge mobility and conductivity compared to inorganic materials, conjugated polymers have extraordinary advantages of solution processability, low cost, light weight, structural versatility, and easy functionality. $\mathrm{CP}$-based organic electronic materials experienced rapid development during the past twenty years and have found broad applications in the field of organic light-emitting diodes (OLEDs) [2-5], organic field-effect transistors (OFETs) [6-8], organic photovoltaics (OPVs) $[9,10]$, and organic thermoelectrics (OTEs) [11,12], etc.

It has been widely accepted that the performance of $\mathrm{CP}$-based devices is greatly influenced by the micro/nano morphologies in bulk or in thin films. For example, many CPs, e.g., poly(3-hexylthiophene) (P3HT) [13], show better charge mobility when polymer chains pack in the "edge-on" orientation (Figure 1a). For OPV devices, the ideal morphology is the interpenetrated lamellar structure, which is beneficial to the charge separation and transportation of electrons and holes to different electrodes (Figure 1b) [14]. As a result, great efforts have been devoted to investigate the controlled formation of desired morphologies. Many factors, such as annealing condition, polymer solution concentration, selection of solvent, mole ratio of binary system, molecular weight, etc., can affect the morphologies of CPs in devices. Therefore, optimizing the morphologies of the active CP-containing layer is critical and one of the most time-consuming steps in device fabrication. In this context, conjugated block copolymers (cBCPs) have been proposed as an ideal solution to 
address this issue, since $\mathrm{CBCPs}$ might combine the advantages of high conductivity and mobility of CPs and morphological versatility and tunability of block copolymers (BCPs).

(a)

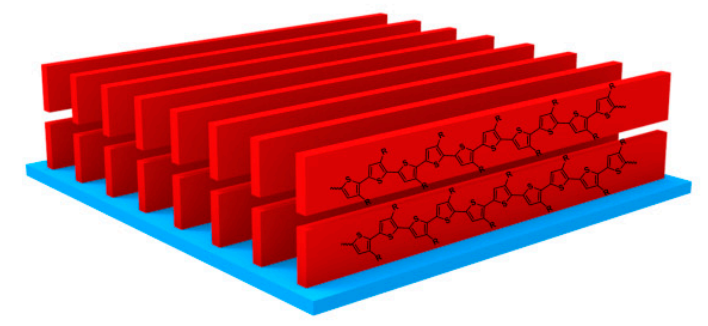

(b)

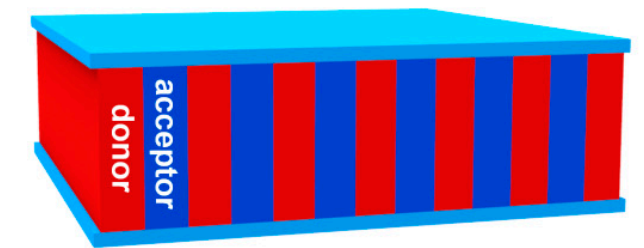

Figure 1. (a) The "edge-on" orientation of poly(3-hexylthiophene) (P3HT) that promotes charge transportation; (b) the proposed ideal interpenetrated lamellar structure of donor and acceptor materials in organic photovoltaics (OPV) devices.

BCPs are comprised of two or more polymeric blocks with different chemical compositions connected by covalent bonds. One of the most remarkable and fascinating features of BCPs is that they can self-assemble into different ordered micro/nano structures both in bulk and in solutions, which makes them good candidates for practical or potential applications at various areas, such as biomaterials, biomedicine, porous materials, nanolithography, organic electronics, etc. [15-24]. The self-assembly of BCPs in bulk has been extensively studied since 1960s, and the experimental and theoretical knowledge is well established [25-33].

In the simplest case of diblock polymers, as shown in Figure 2a, due to the immiscibility of two different blocks, they can self-assemble into different ordered morphologies including spheres (S), cylinders $(\mathrm{C})$, bicontinuous gyroids $(\mathrm{G})$, lamellae $(\mathrm{L})$, etc. The phase separation behaviors of BCPs depend on three parameters: (1) $f$, the volume fractions of the $\mathrm{A}$ and $\mathrm{B}$ blocks $\left(f_{\mathrm{A}}\right.$ and $f_{\mathrm{B}}$, with $\left.f_{\mathrm{A}}+f_{\mathrm{B}}=1\right)$; (2) $N$, total degree of polymerization $\left(N_{\mathrm{A}}+N_{\mathrm{B}}=N\right)$; (3) $\chi$, the Flory-Huggins interaction parameter between two polymer blocks. The driving force of the phase separation is the Gibbs energy change in the selfassembly process, which can divide into mixing enthalpy and mixing entropy. Unlike binary mixture of small molecules or polymer solutions, the mixing entropy of BCPs is usually very small. Thus, the product of $N$ and the $\chi$ parameter, which describes the degree of thermodynamic incompatibility between the two chemically different polymeric blocks, governs the phase separation behaviors in BCP self-assembly. Several theories have been developed to predict the phase separation behaviors of BCP in bulk [25,34]. Nowadays, the self-consistent mean-field (SCMF) theory can predict the phase diagram of BCPs in good agreement with experimental data, as shown in Figure 2b,c. For example, symmetric diblock copolymers $\left(f_{\mathrm{A}}=f_{\mathrm{B}}=0.5\right)$ self-assemble into lamellar morphology when the product $\chi N$ value is larger than the order-disorder transition values $\left((\chi N)_{\mathrm{ODT}}=10.5\right)$ [26]. In addition, many nonclassical spherical packing phases, e.g., Frank-Kasper phases, have also been predicted by SCMF [35] and later experimentally discovered in recent years [36].

Compared to traditional BCPs, the study on CBCPs is still in the seminal stage, despite many recent progresses. A flexible polymer chain is usually considered as a Gaussian chain with a coil configuration, while the polymer chain of CPs is rigid and has a rod-like configuration. Distinguished from the conventional "coil-coil" type BCPs, cBCPs can be divided into two categories, namely, the "rod-coil" and "rod-rod" types (Figure 3). The rigid rod-like backbone of $\mathrm{CPs}$ leads to very different self-assembly behavior of $\mathrm{CBCPs}$ that are distinct from conventional "coil-coil" BCPs. For example, the $(\chi N)_{\text {ODT }}$ for symmetric "rod-coil" and "rod-rod" BCPs is 8.5 and 8.2, respectively, as predicted by R. Borsali et al. [37]. This result indicates that $C B C P s$ containing a rigid block have stronger trend to phase separate than the "coil-coil" BCPs. In addition, conjugated polymer backbones have a strong tendency to form crystalline structures, and the melting temperature $\left(T_{\mathrm{m}}\right)$ of crystalline blocks may also affect the morphology and size of the phase separation. When 
the block segregation strength is very high $\left((\chi \mathrm{N}) /(\chi N)_{\mathrm{ODT}}>3\right)$, crystallization is restricted in the region of phase separation; when the block segregation strength is lower than the critical inter-block segregation strength $\left((\chi \mathrm{N}) /(\chi N)_{\mathrm{ODT}}<1.5\right)$, break-through crystallization occurs to induce the phase separation; when the segregation strength is in an intermediate range $\left((\chi \mathrm{N}) /(\chi N)_{\mathrm{ODT}}=1.5 \sim 3\right)$, the crystallization is not completely restricted to the area of phase separation [38]. However, the self-assembly of cBCPs is very complicated in a real situation due to the strong $\pi-\pi$ interaction between conjugated polymer backbones.
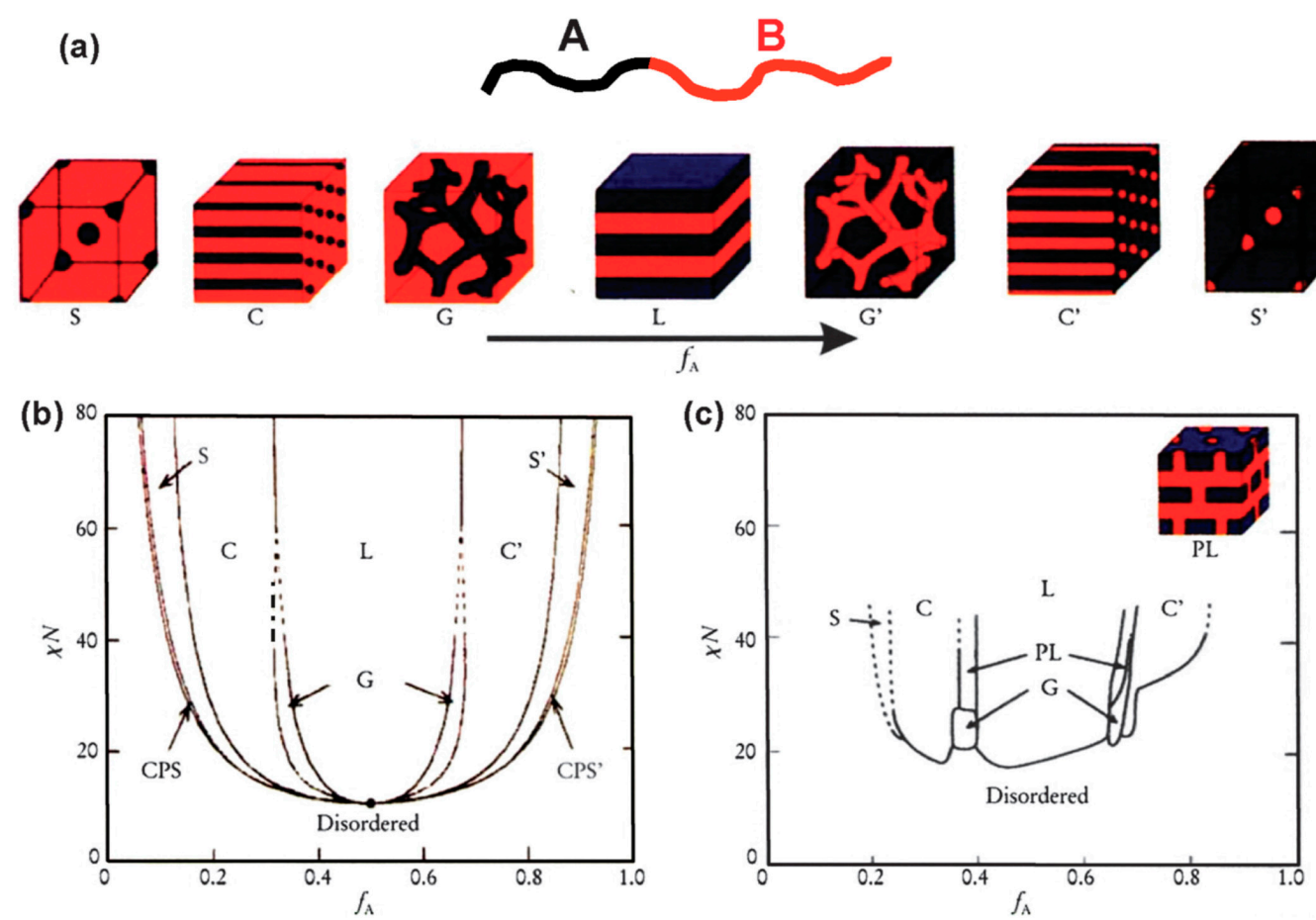

Figure 2. (a) Equilibrium morphologies of $\mathrm{AB}$ diblock copolymers in bulk: $\mathrm{S}$ and $\mathrm{S}^{\prime}=$ body-centered cubic spheres, $\mathrm{C}$ and $\mathrm{C}^{\prime}=$ hexagonally packed cylinders, $\mathrm{G}$ and $\mathrm{G}^{\prime}=$ bicontinuous gyroids, and $\mathrm{L}=$ lamellae. (b) Theoretical phase diagram of $\mathrm{AB}$ diblocks predicted by the self-consistent mean-field theory, depending on volume fraction $(f)$ of the blocks and the segregation parameter, $\chi N$; CPS and CPS' = closely packed spheres. (c) Experimental phase diagram of polystyrene- $b$-polyisoprene copolymers, in which $f_{\mathrm{A}}$ represents the volume fraction of polyisoprene, PL $=$ perforated lamellae. (Reproduced with permission from [28], Copyright Royal Society of Chemistry).

(a)

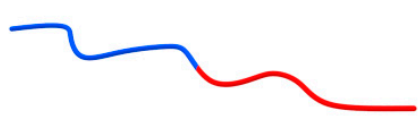

(b)

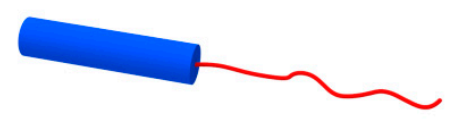

(c)

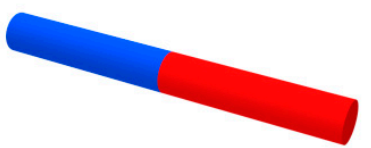

Figure 3. (a) Conventional "coil-coil" block copolymers (BCPs); (b) "rod-coil" conjugated block copolymers (cBCPs); and (c) "rod-rod" cBCPs.

In this review, we focus on synthesis of cBCPs, their self-assembly behaviors, and influencing factors for their micro/nano morphology. In the first part, we summarize the synthetic methods for cBCPs including "rod-coil" and "rod-rod". Second, we discuss how cBCPs self-assemble into different morphologies in bulk, solution and thin film. Thirdly, some influencing factors at the molecular level for cBCP self-assembly will be discussed, including side chain engineering, regioregularity of the backbone, amphiphilic, etc. We also 
discuss the relationship between the device performance and polymer morphologies in third part. Finally, we will give a summary and perspective for CBCPs.

\section{Synthesis of Conjugated Block Copolymers}

As mentioned above, cBCPs are divided into two categories, "rod-coil" (Figure 3b) and "rod-rod" (Figure 3c), based on the type of polymer blocks. "Rod-coil" cBCPs are composed of a rigid CP segment and a flexible polymer chain. Benefitting from the fast development of living polymerization techniques, the synthesis of "rod-coil" cBCPs are extensively studied, and people are able to synthesize various "rod-coil" cBCPs with different chemical components. Figure 4 shows representative chemical structures for rod and coil polymers. However, $\mathrm{CPs}$ are synthesized by metal catalyzed coupling reactions, which usually do not have the "living" feature. In this context, it is still very challenging to synthesize "rod-rod" cBCPs with well-controlled molecular weight and distribution. In this part, we will mainly focus on the synthesis of "rod-coil" and "rod-rod" cBCPs, and a few examples with different topological architecture will be also discussed.
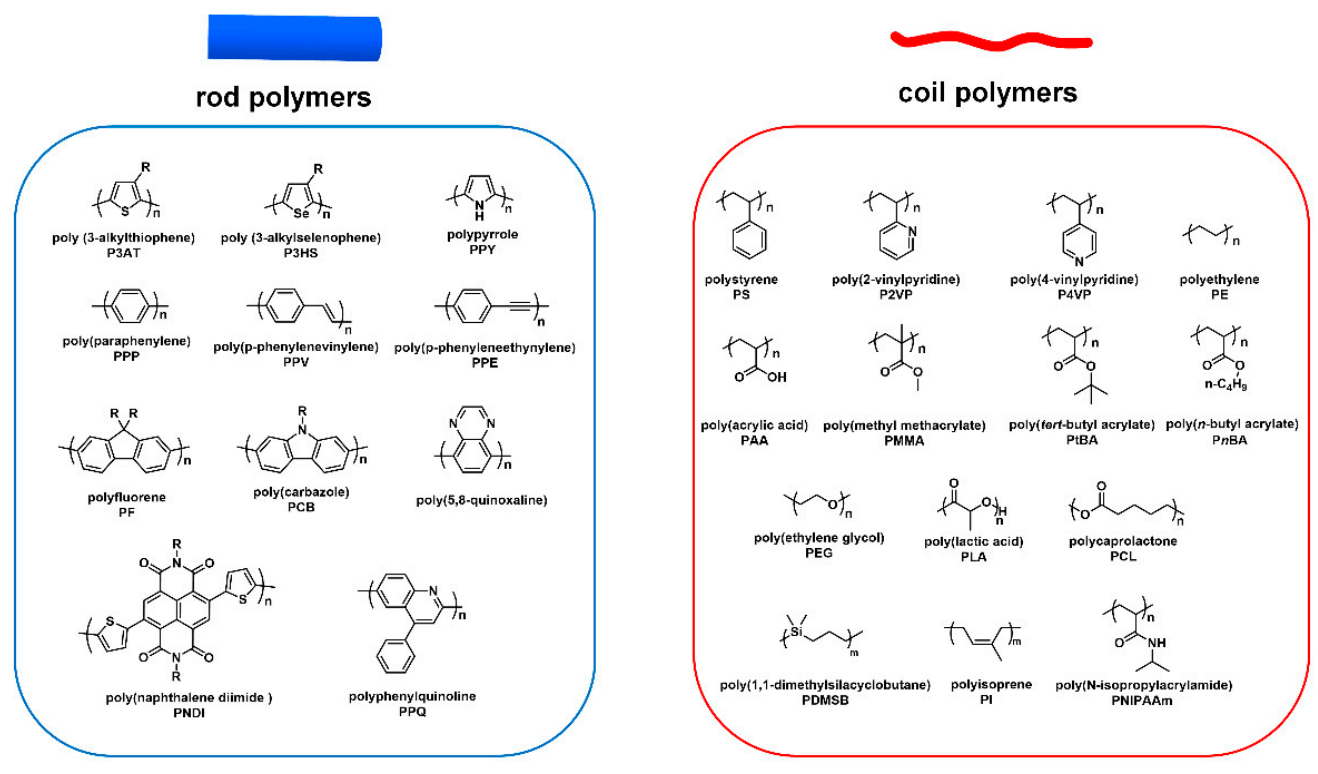

Figure 4. Representative chemical structures for rod and coil polymers.

\subsection{Synthesis of "Rod-Coil" Conjugated Block Copolymers}

Usually, two strategies are employed to synthesize "rod-coil" cBCPs: (i) polymerization from macroinitiator (the grafting-from approach) (Figure 5a), and (ii) the coupling of a pre-synthesized rod and coil block (the grafting-onto approach) (Figure 6a). The rod CP blocks are generally prepared by a transition-metal catalyzed coupling reaction, such as Kumada, Suzuki, and Stille reaction. In order to endow sufficient solubility to CPs, soluble side chains are usually introduced to the backbone, which is critical to subsequent synthesis and processing steps. The coil blocks are normally synthesized from vinyl-based monomers via living/controlled polymerization, such as ionic polymerization, atom transfer radical polymerization (ATRP) [39], reversible addition-fragmentation chain-transfer (RAFT) polymerization [40], and nitroxide-mediated free radical polymerization (NMP) [41]. 

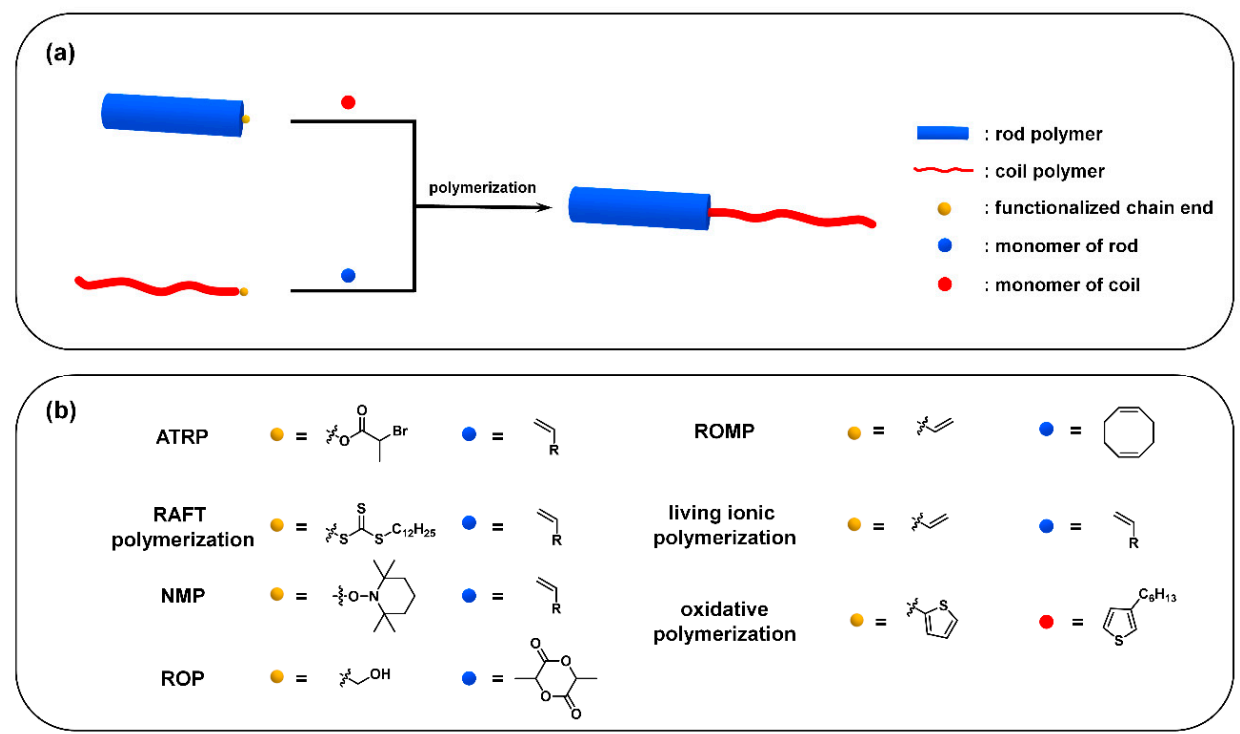

Figure 5. (a) The grafting-from approach from rod polymer and roil polymer; (b) representative functionalized chain end and monomer for different polymerizations.

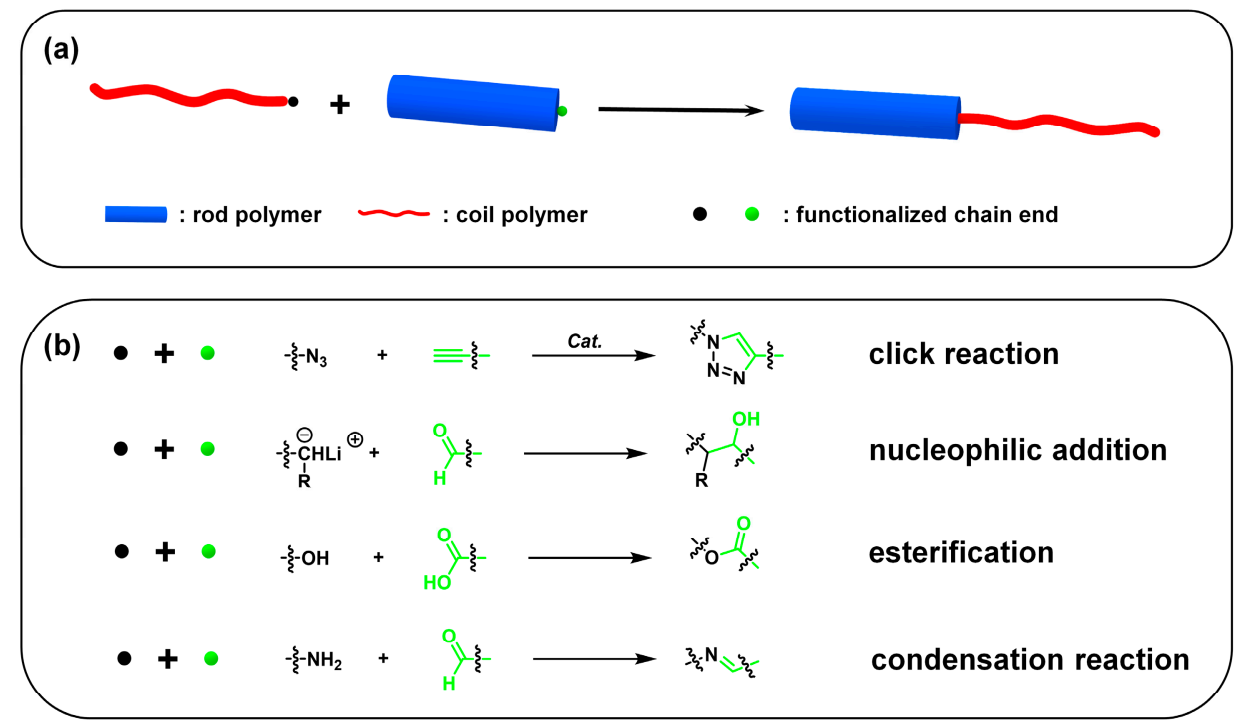

Figure 6. (a) The grafting-onto approach; (b) representative functionalized chain ends and reaction types.

\subsubsection{Grafting-From Approach}

Living/controlled polymerization has been used to prepare rod-coil cBCPs from conjugated macroinitiator via the grafting-from approach. Among them, the ATRP technique is widely used due to its simplicity and applicability of various monomers. Generally, rod blocks are synthesized by transition-metal catalyzed coupling reaction and then functionalized with an ATRP initiator in the chain end for the next living/controlled polymerization step. For example, poly[2,7-(9,9-dihexylfluorene)]-b-poly(tert-butyl acrylate) (PF- $b$ $\mathrm{PtBA}$ ) was synthesized from polyfluorene macroinitiator (PF-Br) by ATRP. Amphiphilic rod-coil cBCPs poly[2,7-(9,9-dihexylfluorene)]-b-poly(acrylic acid) (PF-b-PtAA) were obtained after excess trifluoroacetic acid (TFA) to hydrolyze PF- $b$-PtBA [42]. Liu et al. reported that hydroxy-terminated poly(3-hexylthiophene) (P3HT) was modified by reaction with 2-bromopropionyl bromide to generate macroinitiators, and subsequently, di- or triblock copolymers were synthesized by ATRP [43]. In addition, donor-acceptor type rod-coil cBCP, 
a diblock copolymer (P3HT- $b-\mathrm{C}_{60}$ ) based on P3HT and fullerene, was also obtained by performing ATPR on monomers that attach fullerenes to hydroxyethyl methacrylate through esterification reactions [44]. Different rod-coil cBCPs have been prepared by the ATRP method, including poly(paraphenylene vinylene)- $b$-poly(styrene) (PPV-b-PS) [45], poly(1,4(2,5-dioctyloxy)phenylene vinylene)-b-poly(methyl methacrylate) (PPV-b-PMMA) [46], and poly[2,7-(9,9-dihexylfluorene)]- $b$-poly[2-(dimethylamino)ethyl methacrylate] (PF- $b$ PDMAEMA) [47].

Other living/controlled polymerizations, such as living ionic polymerization, RAFT polymerization, ring-opening polymerization, and NMP, can be also employed to synthesize "rod-coil" cBCPs after installing their corresponding initiators at the end of the rod block. For example, a series of P3HT-based cBCPs were synthesized by using a trithiocarbonate-terminated P3HT macromolecular RAFT agent [48]. Stalmach et al. reported that poly(2,5-dioctyloxy-1,4-phenylene vinylene)- $b$-poly(n-butylacrylate) (PPV-b$\mathrm{P} n \mathrm{BA}$ ) was prepared from an acyclic nitroxide PPV macroinitiator [49]. Dai and coworkers used vinyl end-functionalized P3HT combined with sec-butyllithium to perform the anionic polymerization of 2-vinyl pyridine monomer and finally obtained poly(3-hexylthiophene)$b$-poly(2-vinyl pyridine) (P3HT-b-P2VP) [50]. In addition, Park et al. synthesized poly(3octylthiophene)- $b$-poly (ethylene oxide) (POT-b-PEO), which uses hydroxyl-terminated $\mathrm{POT}$ and then initiates anionic ring-opening polymerization of ethylene oxide under the catalysis of potassium naphthalide [51].

Ring-opening polymerization (ROP) and ring-opening metathesis polymerization (ROMP) have been also used to prepare "rod-coil" cBCPs. For example, hydroxyl endfunctionalized poly(3-alkylthiophene)s (P3ATs) were used as macroinitiators for the controlled ROP of D,L-lactide to afford poly(3-alkylthiophene)- $b$-polylactide (P3AT- $b$-PLA) [52] Radano et al. reported that block copolymers poly(3-hexylthiophene)- $b$-polyethylene (P3HT- $b$-PE) were synthesized through the chain transfer of olefin-terminated P3HT in the presence of cyclooctene via ring-opening metathesis polymerization (ROMP) [53].

Similarly, "coil" block-based macroinitiators are prepared by chain-end functionalization and subsequently used for synthesizing "coil-rod" cBCPs. For example, Cuendias et al. also report a synthetic route of using a coil block as an initiator to polymerize the rod part. They synthesized a bromine-containing thiophene derivative to perform ATRP on the end of the bromine and then conducted oxidative polymerization on the thiophene part to afford poly(3-hexylthiophene)- $b$-poly(n-butyl acrylate) (P3HT- $b-\mathrm{P} n \mathrm{BA})$ [54]. However, this strategy is not widely applied due to non-trivial synthesis.

\subsubsection{Grafting-Onto Approach}

For the grafting-onto approach, a "coil" block and "rod" block are synthesized individually by different types of polymerization. Then, the as-prepared two blocks are functionalized with a specific group in the chain end, which can be coupled with each other (Figure 6a). A highly efficient "click" reaction is usually used for the grafting-onto approach. Polymers synthesized by ATRP are easily introduced to the azide group in the chain end by nucleophilic substitution reaction and then react with alkyne functionalized CPs by the copper (I) catalyzed "click" reaction to afford "rod-coil" cBCPs. For example, $\mathrm{Li}$ et al. synthesized poly(3-hexylthiophene)-b-poly(tert-butyl acrylate) (P3HT-b-PtBA) by ethynyl end functionalized P3HT and azide functionalized PtBA, in which PtBA was prepared by ATRP [55]. Lohwasser et al. modified the alkynyl group at the end of P3HT, which was followed by a click reaction with poly(4-vinylpyridine)(P4VP) polymerized by NMRP to obtain P3HT- $b$-P4VP [56]. Saejin et al. also used P3HT modified with an alkynyl group to react with azide functionalized PEG to obtain P3HT- $b$-PEG through a click reaction [57]. Other reactions are also employed for the grafting-onto approach, such as esterification, nucleophilic addition, condensation reaction, etc. For example, oligo(phenylene vinylene)- $b$-poly(ethylene glycol)(OPV- $b$-PEO) could be prepared through the esterification reaction between OPV with a carboxyl end and poly(ethylene glycol) monomethyl ether [58]. Olsen et al. reported the synthesis of poly(2,5-di(2'-ethylhexyloxy)- 
1,4-phenylene vinylene)- $b$-poly(1,4-isoprene) (PPV-b-PI). Benzene solution of aldehydeterminated PPV was injected to quench an anionic polymerization of isoprene to afford the desired PPV-b-PI [59].

\subsection{Synthesis of "Rod-Rod" Conjugated Block Copolymers}

Compared to "rod-coil" cBCPs, the synthesis of "rod-rod" cBCPs is still very challenging, and many reported studies in the literature mainly focus on the poly(3-alkylthiophene) (P3AT) system prepared by Grignard metathesis (GRIM) polymerization (Figure 7a) [60-66]. GRIM polymerization, also known as Kumada catalyst transfer polymerization (KCTP), was developed by McCullough's group in 1999 [67]. Due to its living nature, GRIM polymerization provides a versatile tool to synthesize regioregular poly(3-alkylthiophene) (P3AT) with well-controlled molecular weight, narrow distribution, and good chain-end functionality [68]. For example, Lee and coworkers used sequential GIRM polymerization to obtain poly(3-dodecylthiophene)-b-poly(3-(2-(2-(2-methoxyethoxy)ethoxy)ethoxy)methyl thiophene) copolymer (P3DDT- $b$-P3TEGT) [65]. GRIM polymerization can also be used to synthesize donor-acceptor type "rod-rod" cBCPs. Block copolymers poly(3-hexylthiophene)- $b$ poly(benzotriazole) (P3HT- $b$-PBTz) were prepared by the sequential monomer addition of benzotriazole and thiophene [66].
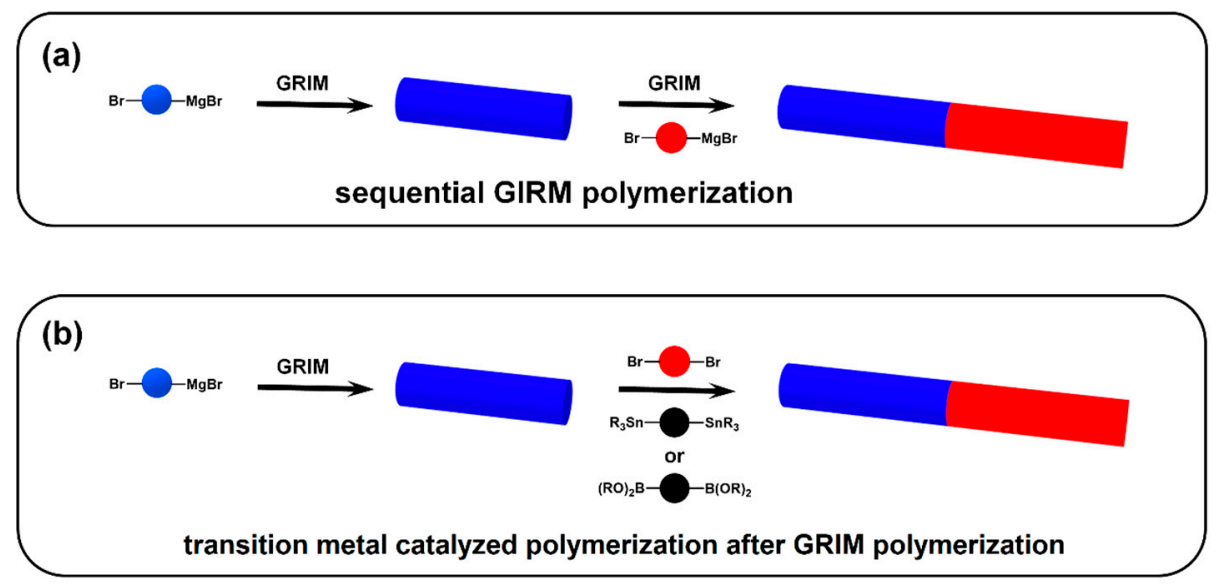

Figure 7. (a) The grafting-onto approach; (b) representative functionalized chain ends and reaction types.

Other types of transition metal catalyzed coupling reactions have also been used to prepared "rod-rod" cBCPs (Figure 7b) [69-74]. Lin et al. employed GRIM and Suzuki-Miyaura polycondensation to prepared a seriels of "donor-acceptor" cBCPs including P3HT- $b$ poly $\left(9^{\prime}, 9^{\prime}\right.$-dioctyl fluorene) (P3HT- $b$-PF), P3HT- $b$-poly $\left(9^{\prime}, 9^{\prime}\right.$-dioctyl fluorene -alt- benzothiadiazole) (P3HT- $b$-PFBT), and P3HT- $b$-poly $\left(2,7-\left(9^{\prime}, 9^{\prime}\right.\right.$-dioctyl-fluorene)-alt-5,5-(4' $7^{\prime}$-di-2thienyl-2', $1^{\prime}, 3^{\prime}$-benzothiadiazole) (P3HT- $b$-PFTBT) [71]. Ku et al. also used bromineterminated $\mathrm{P} 3 \mathrm{HT}$ and $\mathrm{AA}+\mathrm{BB}$ monomer to conduct Stille polymerization to prepare poly(3-hexylthiophene)- $b$-poly(diketopyrrolopyrrole-terthiophene) (P3HT- $b$-DPP) [72] .

In recent years, a new type of "rod-rod" cBCPs was reported. Unlike fully conjugated "rod-rod" block copolymers, two conjugated blocks are connected by a flexible short alky chain to afford donor- $\sigma$-acceptor type "rod-rod" cBCPs. For example, Lee et al. prepared two types of cBCPs, PTQI- $b$-PNDIS and PTQI- $b$-PNDISL, containing quinoxaline-thiophene (PTQI) and naphthalene dicarboximide-selenophene (PNDIS) blocks, in which PTQI- $b$ PNDIS is fully conjugated and PTQI- $b$-PNDISL is composed of a donor and acceptor block connected by non-conjugated alkylene spacer [75].

\subsection{Other Types of $c B C P s$}

cBCPs with complex architectures have been reported, such as conjugated multiblock copolymers [76-78], miktoarm star copolymers [79-83], polymer brushes [84,85], 
dendrimers [86], cyclic polymers [87], etc. Similar to binary cBCPs, polymers of other architectures can also be synthesized by using the grafting-from approach and graftingonto approach. For the grafting-from approach, Lee et al. reported PDMSB- $b$-PS- $b$-PMMA synthesized by sequential anionic polymerization [78]. There are also some miktoarm star copolymers prepared by combining grafting-from and grafting-onto, such as (P3HT) PMMA [82], (P3DDT) $)_{2}$ PMMA [80], PMMA ${ }_{2}$ P3HT [81], etc. For polymer brushes, it is usually used to modify the polymer on norbornene to form a macromonomer and then synthesize conjugated polymer brushes through ROMP, such as P3HT- $b$-PLA brush copolymers [85]. With the current development of synthesis methods, there are relatively few studies on the synthesis and phase separation of complex architectures, and this field still needs to be expanded.

\section{Self-Assembly of cBCPs}

\subsection{In Bulk}

A lot of research has been published on the topic of "rod-coil" BCP self-assembly. "Rod-coil" BCPs show remarkably rich structural morphologies in bulk, such as lamellar phases, spherical, cylindrical, smectic, C-type smectic, O-type structure (HPL), hexagonal puck phases, hexagonally perforated layer structures, etc. [50,88-91]. Theoretical calculations also predict that A15 and gyroid phases could also exist in "rod-coil" BCPs. In the study of PPV-b-P4VP, Sary et al. found that they can form spherical, hexagonal columnar, lamellar, and smectic phases, based on volume fraction of PPV [92]. These results are consistent with theoretical predictions (Figure 8) [93]. However, for the conjugated "rod" blocks, they have a strong $\pi-\pi$ interaction and are easy to crystallize and thus form fiber structures. The self-assembly of cBCPs is more complicated and different from "rod-coil" BCPs. The interaction between the anisotropic conjugated rods should be considered.

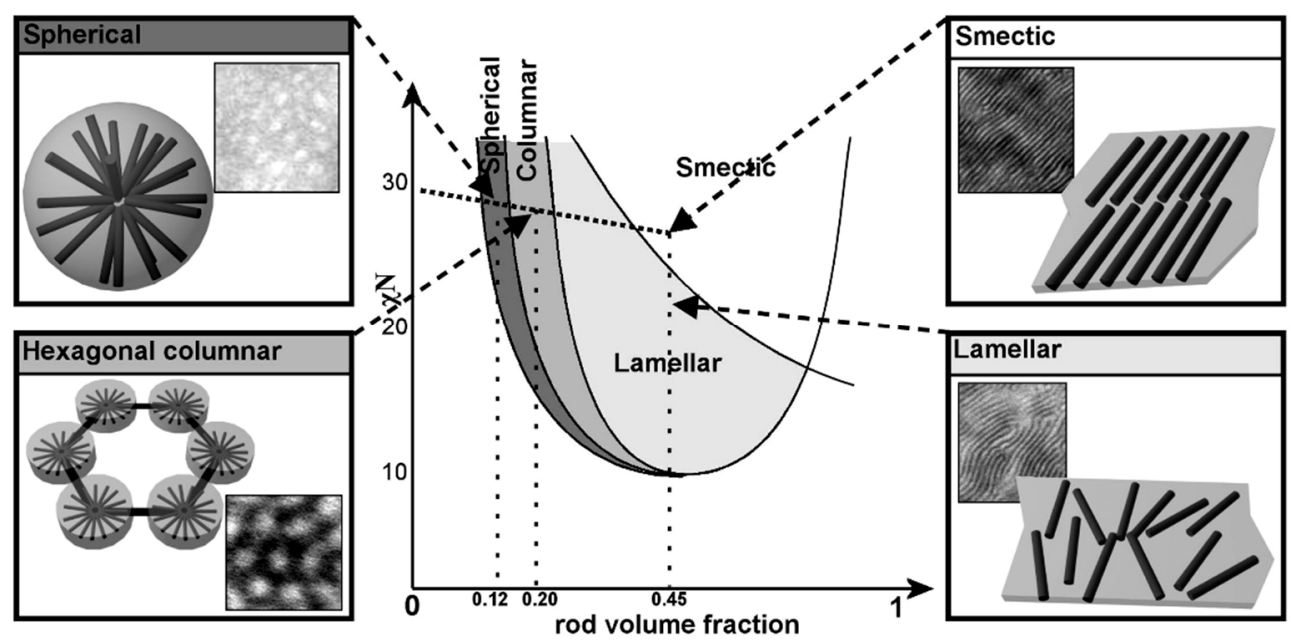

Figure 8. Comparison between the phase diagram predicted by Landau expansion theories for rod-coil block copolymers and the microphase-separated morphologies experimentally observed for PPV-P4VP block copolymers. (Reprinted with permission from Ref [92]. Copyright American Chemical Society).

For "rod-rod" cBCPs, only a few examples were reported. Due to the strong interaction "rod-rod" between blocks, i.e., $\pi-\pi$ interaction and crystallization, it is difficult to prepare ordered nanostructures. The morphologies of "rod-rod" cBCPs are affected by the competition between rod-rod interaction and phase separation. The theory of "rod-rod" CBCP self-assembly is not yet clear, and their phase separation is generally independent of its specific chemical structure and composition. Noting that due to the high rigidity and poor curl ability of rod blocks, aggregates with curvature, e.g., spherical, are seldom formed in "rod-rod" cBCPs [94]. 


\subsection{In Solution}

One key research area of $\mathrm{CBCPs}$ is their self-assembly behaviors in solution. Amphiphilic "rod-coil" cBCPs will self-assemble into various nanostructures depending on the molecular structures. Usually, amphiphiles with a hydrophobic chain and a hydrophilic head could self-assemble into spherical micelle, cylindrical micelle, vesicle, and lamellae (Figure 9), which can be predicted by the packing parameter, $P=v /\left(a_{0} l_{c}\right)$, in which $v$ is the volume of the hydrophobic chain, $a_{0}$ is the polar head surface at the critical micelle concentration ( $\mathrm{cmc}$ ), and $l_{c}$ is the hydrophobic chain length [95]. Based on this theory, the aggregates of amphiphilic "rod-coil" cBCPs in solution could be tuned by changing the ratio of rod/coil. Kim et al. reported that a series of carbohydrate conjugate rod-coil amphiphiles with different rod/coil ratios are able to self-assemble into spheres, vesicles, and cylinders $[96,97]$. Selective solvent concentration is another parameter that affects the morphologies of amphiphilic "rod-coil" cBCPs in solution. For example, poly(phenylquinoline)- $b$-polystyrene(PPQ- $b$-PS) formed lamellar structures in dichloromethane/trifluoroacetic acid(DCM/TFA) $(v / v=1)$ mixed solvent and cylinders in $\mathrm{DCM} / \mathrm{TFA}(v / v=1 / 9)$ at room temperature. TFA is a good solvent for the conjugated PPQ block and protonates its imine nitrogen, while the coil PS block is insoluble in TFA [98]. Tung et al. reported that PF-b-PAA formed a tape-like structure when the coil part is short. When PAA block increased, various morphologies were observed with methanol concentration [42]. In addition to rod/coil ratios and selective solvent concentration, there are also other parameters that drive the self-assembly of "rod-coil" cBCPs in solution including $\mathrm{pH}$ values, temperature, the presence of additives and block compositions, etc. Several comprehensive reviews related to "rod-coil" cBCPs have been published [99-104].

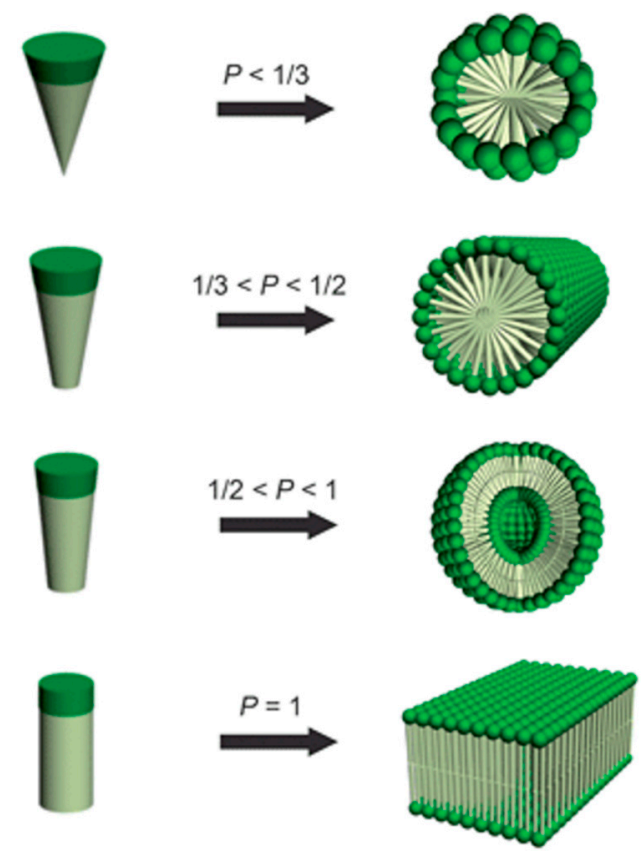

Figure 9. Dependence of nanostructure morphologies on the relative volume fraction of hydrophobic and hydrophilic blocks. (Reprinted with permission from Ref [95]. Copyright Royal Society of Chemistry).

\subsection{In Thin Film}

Semiconducting CPs can be processed in organic solvents, and their electronic properties are largely determined by the nanostructure of the film. The orientation of polymer backbone is very important and has a remarkable effect on the charge mobility. Sirringhaus et al. found that mobility of edge-on orientated P3HT was two orders of magnitude of face-on orientated P3HT in 1999 [105]. Due to the anisotropy of transport properties, 
when semiconducting CPs self-assemble into edge-on lamellar morphology, charge transportation is more favorable compared to face-on orientation. Serials of "rod-coil" cBPCs were synthesized and their morphologies were investigated, including P3HT- $b$-PS, P3HT$b$-PI, P3HT- $b$-PMMA, P3HT- $b$-PEG, etc. For example, Oh et al. designed a P3HT- $b$-PEG polymer in which PEG was amphiphilic and could cause self-assembly at a gas-liquid interface. P3HT- $b$-PEG thin films prepared on an inclined water surface have a long-range order and direction-controlled P3HT nanowire arrays, which have better hole mobility than P3HT- $b$-PEG thin films prepared on a flat water surface [57]. Han et al. found that P3DDT$b$-PLA could self-assemble into lamellar morphology in thin film after solvo-microwave annealing, in which a P3DDT block has an edge-on orientation [106].

In "rod-coil" cBCPs, the coil block are generally insulating polymers and therefore will lower the carrier concentration, limiting their device performance. In this context, all conjugated "rod-rod" cBCPs have become a focus of interest. Several conjugated "rodrod" cBCPs have been synthesized with excellent charge-transporting mobility, and their thin film morphologies were also investigated [61-63,107-110]. Zhang et al. synthesized a series of highly regioregular poly(3-hexylthiophene-b-3-(2-ethylhexyl)thiophene)s (P3HT- $b$-P3EHT) and found that the P3EHT block could induce the self-assembly of P3HT in thin film (Figure 10a) [62]. For poly( $p$-phenylene)-b-(3-hexylthiophene) (PPP$b$-P3HT), Yang et al. discovered that edge-on and face-on orientation could be tuned by different annealing processes (Figure 10c) [111]. End-on orientation is also achieved by "rod-rod" cBCPs. Lee et al. prepared poly(3-dodecylthiophene)-b-poly(3-(2-(2-(2methoxyethoxy)ethoxy)ethoxy)methyl thiophene) copolymer (P3DDT- $b$-P3TEGT). A P3DDT$b$-P3TEGT thin film showed parallel oriented lamellar microdomains to the substrate in which the polymer backbones are perpendicular to the substrate and thus show improved hole mobility along the vertical direction compared with P3DDT (Figure 10b) [65].

(a)

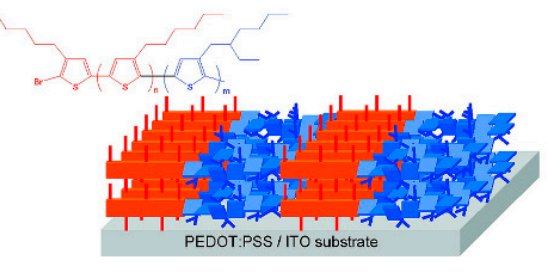

(b)

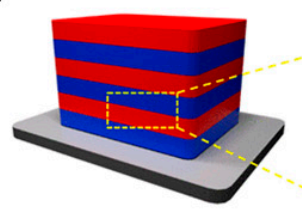

(c)

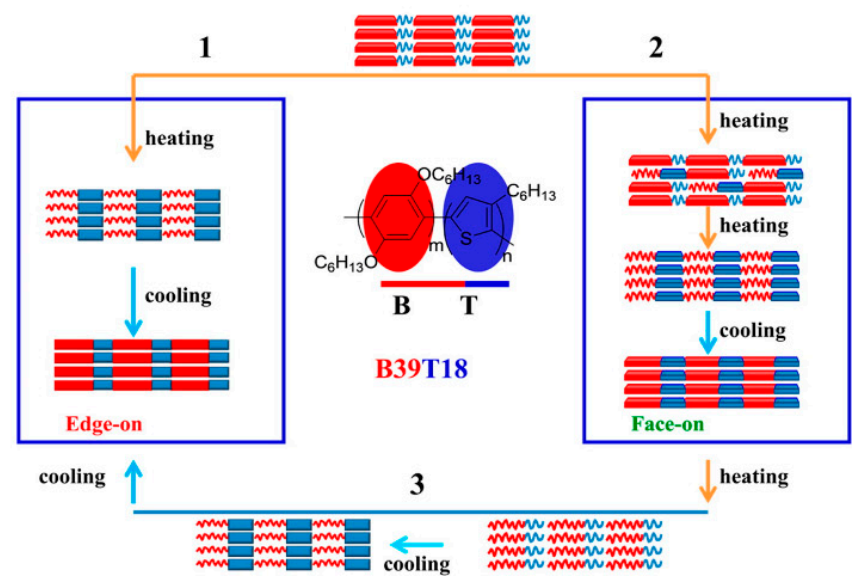

Figure 10. (a) "Edge-on" orientation of poly(3-hexylthiophene- $b$-3-(2-ethylhexyl)thiophene)s (P3HT- $b$-P3EHT) in thin film; (Reprinted with permission from Ref [62]. Copyright American Chemical Society); (b) "end-on" orientation of poly(3dodecylthiophene)- $b$-poly(3-(2-(2-(2-methoxyethoxy)ethoxy)ethoxy)methyl thiophene) copolymer (P3DDT- $b$-P3TEGT) in thin film; (Reprinted with permission from Ref [65]. Copyright American Chemical Society); (c) three different selfepitaxial crystallization circles by controlling the heating process for poly( $p$-phenylene)- $b$-(3-hexylthiophene) (PPP- $b$-P3HT). (Reprinted with permission from Ref [111]. Copyright American Chemical Society).

For binary donor-acceptor mixed bulk heterojunction (BHJ) solar cells, it is very challenging to fully control the nano-phase separation in order to achieve better exciton dissociation at the donor-acceptor interface. Using $\mathrm{CBCP}$ is considered to be an ideal solution to resolve this problem, even though great efforts have been made to tune the morphology of the active layer, including the choice of casting solvent, solvent evaporation rate, and thermal or solvent annealing. In 2000, Stalmach et al. reported a diblock copolymer 
composed of PPV and polystyrene functionalized with fullerenes(PSFu), in which PS blocks are partially functionalized with fullerene. In a spin-cast film of PPV- $b$-PSFu, a micrometerscale, honeycomb-like nanostructure is obtained, and luminescence from PPV is quenched indicating efficient electron transfer to $C_{60}$ [112]. Zhang et al. report that "rod-coil" donoracceptor copolymer poly(thiophene- $b$-perylene diimide) copolymer P3HT- $b$-PDI formed fibrillar morphology in thin film after solvent vapor annealing and gave a power conversion efficiency of $0.49 \%$ in a solar cell device. A donor-acceptor type "rod-rod" block can self-assemble into a donor-acceptor alternating lamellar nanostructure, which is beneficial for exciton dissociation in organic solar cells. Guo et al. designed and prepared a novel donor-acceptor type poly(3-hexylthiophene)- $b$-poly((9,9-dioctylfluorene)-2,7-diyl-alt-[4,7bis(thiophen-5-yl)-2,1,3-benzothiadiazole]-2',2"'-diyl) (P3HT-b-PFTBT) block copolymer. By using P3HT- $b$-PFTBT as an acting layer, 3\% efficiency was achieved for OPV devices. $X$-ray scattering results demonstrated that the high device performance of P3HT- $b$-PFTBT was due to self-assembly into lamellar structures with primarily face-on crystallite orientations [14].

\section{Factors that Affect the Self-Assembly of cBCPs}

Many factors will affect the self-assembly of cBCP. Similar to conventional "coilcoil" BPCs, $f, N$, and $\chi$ could be adjusted to tune the morphology of cBCPs. In addition, other parameters, such as side chains, regioregularity of the conjugated backbone, blockblock connecting linkers, etc., will also affect cBCP self-assembly.

\subsection{Volume Fraction $(f)$}

Similar to "coil-coil" BCPs, the morphologies of cBCPs can be tuned by adjusting the volume fraction of each block $[50,113]$. For example, Dai et al. reported that a series of welldefined P3HT- $b$-P2VP, synthesized by GRIM and anionic polymerization, showed sphere, cylinder, lamellae with an increase of P3HT content and finally, a nanofiber structure appeared when the mass fraction of P3HT was greater than 50\% [50]. Sary et al. found that the morphologies of PPV- $b$-P4VP changed from a lamellar structure to spherical structure as the $f_{\mathrm{P} 4 \mathrm{VP}}$ increased (Figure 11) [92]. Lee et al. also reported that P3HT- $b$-P2VP formed a lamellar structure when $f_{\mathrm{P} 2 \mathrm{VP}}=0.30-0.60$ and the copolymer exhibited cylindrical and spherical phases when $f_{\mathrm{P} 2 \mathrm{VP}}=0.60-0.80$. The phase diagram of P3HT- $b$-P2VP was constructed based on the experimental results, noting that the gyroid phase of cBCP was first found in P3HT- $b-\mathrm{P} 2 \mathrm{VP}\left(f_{\mathrm{P} 2 \mathrm{VP}}=0.68\right)[113]$.
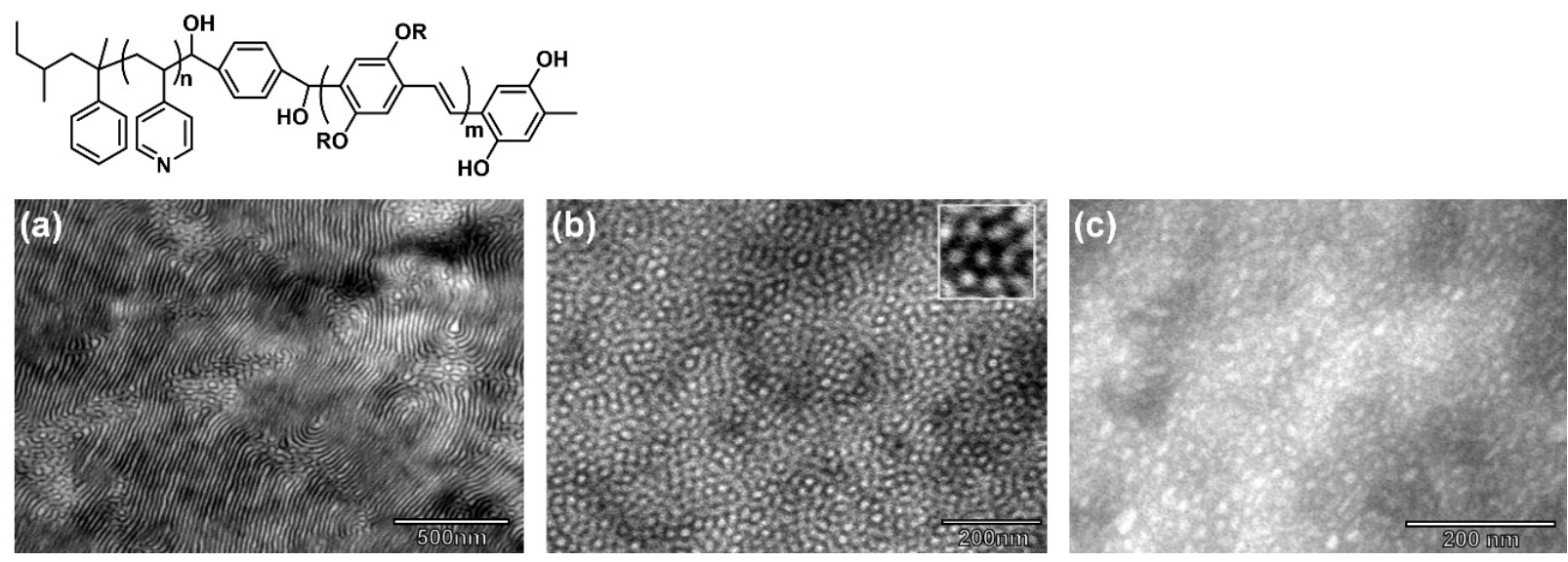

Figure 11. Iodine-stained TEM micrographs of (a) $\mathrm{PPV}_{11}-b-\mathrm{P}_{4} \mathrm{VP}_{51}$ (ordered lamellar structure); (b) $\mathrm{PPV}_{11}-b-\mathrm{P}_{4 \mathrm{VP}} 173$ (ordered hexagonal phase); (c) $\mathrm{PPV}_{11}-b-\mathrm{P}_{4} \mathrm{VP}_{295}$ (poor order of spherical phase). (Reprinted with permission from Ref. [92]. Copyright American Chemical Society). 


\subsection{Block-Block Interactions ( $\chi$ and $\mu$ )}

For $\mathrm{CBCPs}$, the morphology is not only governed by enthalpic interaction, which is defined as a Flory-Huggins interaction parameter $(\chi)$, but it is also affected by the Maier-Saupe parameter $(\mu)$, which characterizes the rod-rod interactions. For example, Lee et al. prepared a series of P3HT- $b$-P2VP block copolymers [113]. When $\chi N_{\text {total }}$ $>\mu N_{\mathrm{P} 3 \mathrm{HT}}$, the polymer tends to microphase separation to produce various microphase structures including lamellae, cylinder, sphere, and gyroid; otherwise, the polymer forms a nanofiber morphology. Especially, for donor-acceptor $\mathrm{CBCPs}$, the donor and acceptor block have a strong interaction, which makes $\chi$ very small or even negative, leading to a difficulty of self-assembly.

\subsection{Degree of Polymerization (N)}

The microphase separation from the traditional coil-coil copolymer suggests that increasing N promotes phase separation. Kynaston et al. synthesized Poly(3-dodecylthiophene)$b$-poly(3-dodecylselenophene) (P3DDT- $b$-P3DDS) with a block ratio of approximately 1:1 (Figure 12). When the degree of polymerization is relatively low $(N<35)$, lamellar structures are formed due to the crystallization of each block. However, when $\mathrm{N}$ is increased, thiophene and selenophene blocks co-crystallize into fibers $(N=50-60)$ and patchy fiber $(N>80)$. Field-effect transistors testing showed that co-crystalline fibers have the best device performance [114].
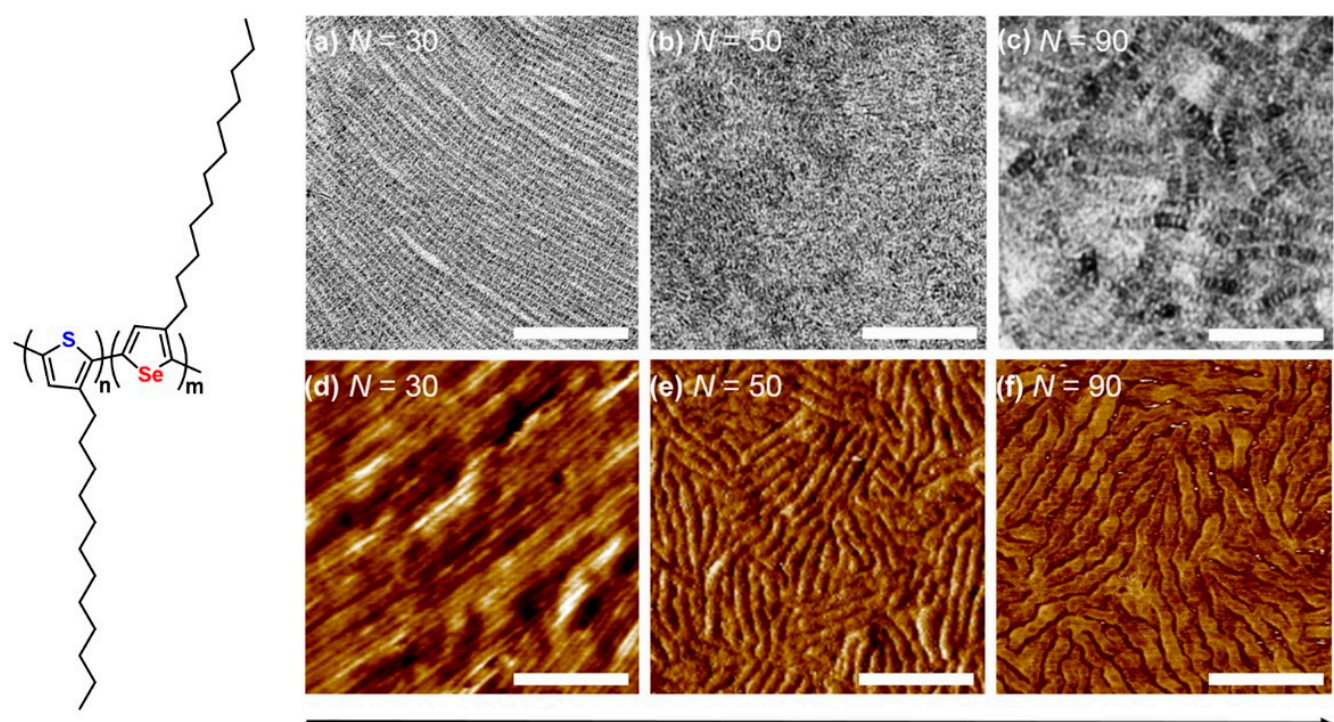

Increasing $N$

Figure 12. TEM micrographs and tapping-mode AFM phase images of P3DDT- $b$-P3DDS BCPannealed thin films depicting lamellar structures $((\mathbf{a}, \mathbf{d}), N=30)$, co-crystallized fibers $((\mathbf{b}, \mathbf{e}), N=50)$, and a patchy fiber morphology $((\mathbf{c}, \mathbf{f}), N=90)$. Scale bars are $200 \mathrm{~nm}$. (Reprinted with permission from Ref. [114]. Copyright American Chemical Society).

\subsection{Side Chain Engineering}

In the synthesis of CPs, soluble side chains are usually introduced to the rigid polymer backbone not only because they can endow polymers with sufficient solubility but also they can tune the packing and morphologies of polymer chains [115-117]. P3HT has a strong $\pi-\pi$ interaction and tends to crystallize at room temperature. Replacing hexyl with a longer or branched side chain will largely decrease $\pi-\pi$ interaction, leading to micro phase separation. Lin et al. synthesized three different poly(3-alkylthiophene)-b-poly(methyl methacrylate)(P3AT- $b$-PMMA)s by changing the length of the side chain of thiophen. At approximately $f_{\mathrm{P} 3 \mathrm{AT}}=0.5$, P3AT- $b$-PMMA showed versatile morphology depend on the side chain length of thiophene, and the $\chi$ value was also calculated (Figure 13a) [118]. 
Guo et al. found that all conjugated block copolymers, P3HT- $b$-PFTBT, self-assemble into a small domain size $(<10 \mathrm{~nm})$ after introducing a side chain into the PFTBT unit, leading to poor OPV performance. This probably is because the miscibility of P3HT and PFTBT has become better, resulting in weaker phase separation [14].

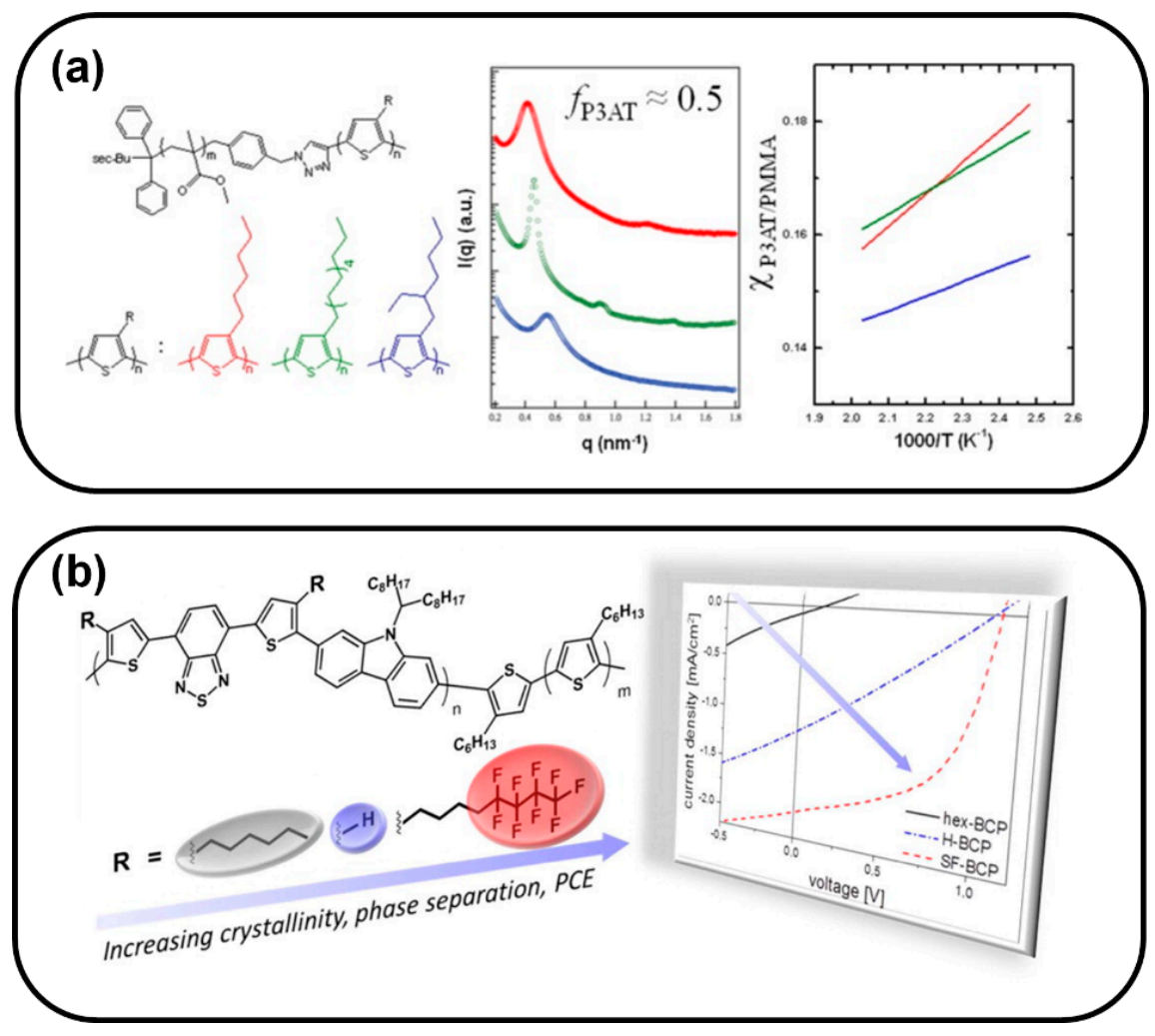

Figure 13. (a) Chemical structures of P3AT- $b$-PMMAs with different side chain length, Small-angle $X$-ray scattering results and temperature dependence of the Flory-Huggins interaction parameter between P3AT and PMMA segments for P3AT- $b$-PMMA; (Reprinted with permission from Ref. [118]. Copyright American Chemical Society); (b) chemical structure of PCDTBT- $b$-P3HT with different side chains and $J-V$ characteristics. (Reprinted with permission from Ref. [119]. Copyright American Chemical Society).

All conjugated donor-acceptor BCPs always suffer from poor ability to phase separate due to the strong interaction between the donor and acceptor blocks. Introducing immiscible side chains into different blocks, which can increase the $\chi$ between the donor and acceptor blocks, can resolve this problem. For example, Mitchell et al. designed an amphiphilic block copolymer P3HT- $b$-PFTBT with a hydrophilic tetraethylene glycol side chain attached to the acceptor [35]. This structure can better control the microphase separation and can form well-defined structures in thin film. However, the performance of devices prepared from this material was unexpectedly low, which was probably due to poor electron transport through steric-induced twisting of the acceptor backbone. Adding fluorinecontaining side chains can also increase the incompatibility between blocks. Lombeck et al. prepared SF-PCDTBT- $b$-P3HT in which the side chain on the donor unit was fluorinated (Figure 13b). This material has a strong tendency of phase separation due to the introduction of semi-fluorinated side chains. A bi-continuous structure, which is beneficial for charge separation and charge transfer, is formed, leading a power conversion efficiency of $1 \%$ when using this block polymer as an active layer in a solar cell device [119]. 


\subsection{Regioregularity}

For P3AT-based "rod-coil" cBCPs, the morphologies in bulk or thin film can be modulated by controlling over the regioregularity (RR) of the P3AT block. Kim et al. designed a series of P3HT- $b$-P2VP with different RR. High RR P3HT- $b$-P2VP has a very strong interchain interaction and is preferential to crystalline, which makes it difficult to form an ordered nanostructure. In contrast, crystallization is inhibited in low RR P3HT-b-P2VP and well-ordered nanostructures are achieved, i.e., lamellar and cylindrical phases [120]. They also found that the domain space of poly(3-dodecylthiophene)-b-poly(2-vinylpyridine) (P3DDT- $b$-P2VP) can be tuned by regulating the RR of the P3DDT block (Figure 14) [121].

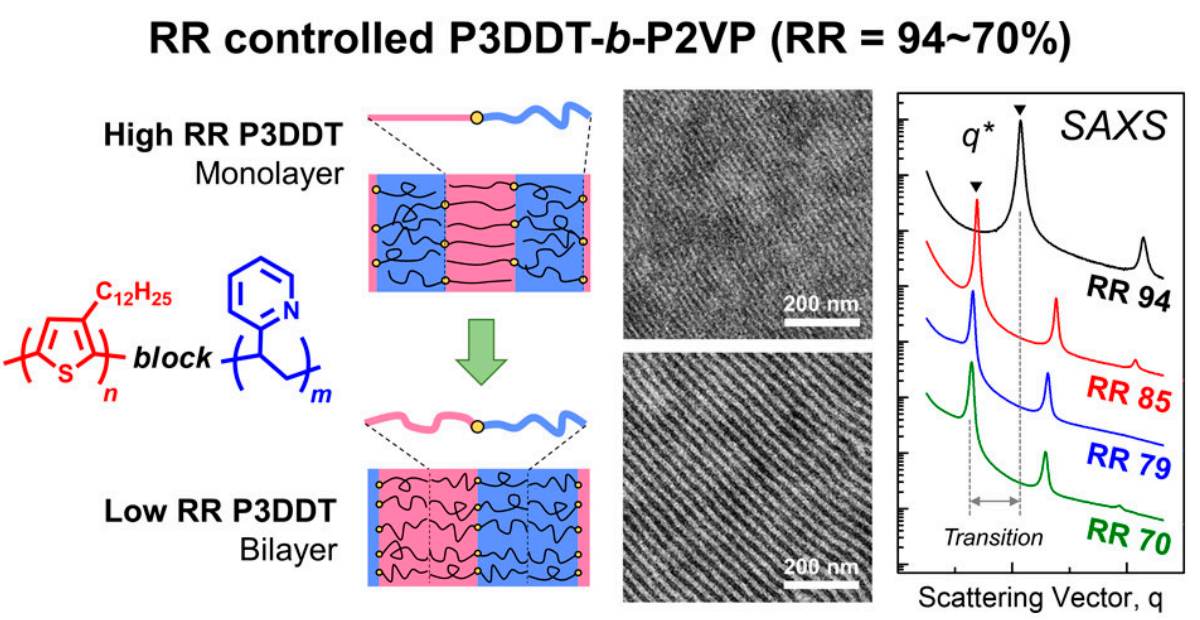

Figure 14. Chemical structure of P3DDT- $b$-P2VP and their morphological results from TEM and SAXS characterization. (Reprinted with permission from Ref. [121]. Copyright American Chemical Society).

In addition, RR also affects the crystalline temperature of PAHT and subsequently has an influence on the self-assembly behaviors. For example, the crystal growth of low RR (70-80\%) P3DDT- $b$-P2VP, which has a low crystallization temperature below the glass transition of P2VP, is confined by the cylindrical or lamellar BCP structure. The phase separation is dominated by rod-coil segregation. Thus, high RR (94\%) P3DDT- $b$-P2VP crystalline at a temperature higher than the glass transition of P2VP and only a lamellar structure is formed, which is attributed to the geometric compatibility between crystal growth and self-assembled symmetry [122].

\subsection{The Influence of Middle Bridge}

For "rod-rod" cBCPs, the block-block connecting linker can be tuned to control the interface between the donor and acceptor domain in bulk or thin film [100]. Lee et al. synthesized two types of cBCPs (Figure 15a), which were PTQI- $b$-PNDIS with two blocks connected by a $\pi$ conjugated unit and PTQI- $b$-PNDISL with two blocks connected by a nonconjugated spacer. They found that PTQI- $b$-PNDISL shows a more prominent nanophase behavior compared to PTQI- $b$-PNDIS. In addition, because of the flexible spacer buffer between the two blocks, each block appears as an independent crystallization behavior leading to the power conversion efficiency of PTQI- $b$-PNDISL as high as $1.54 \%$, while PTQI$b$-PNDIS is only $0.36 \%$ (Figure $15 b$ ) [75]. 
(a)

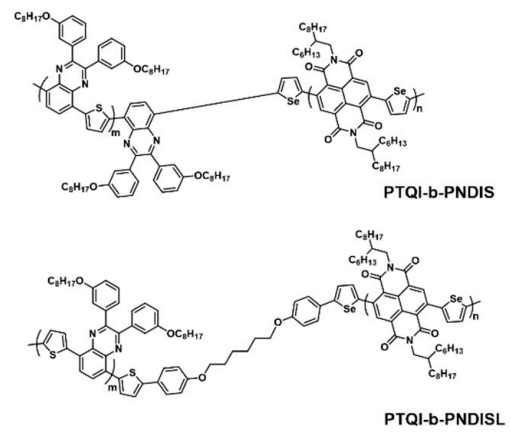

(b)

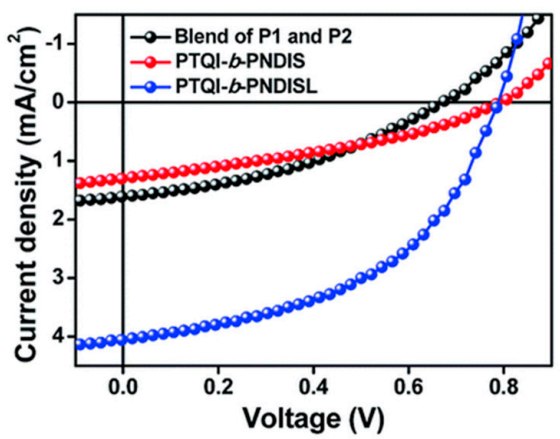

Figure 15. (a) Chemical structures of conjugated PTQI- $b$-PNDIS and donor- $\sigma$-acceptor type PTQI- $b$ PNDISL; (b) $J-V$ characteristics of (red) PTQI- $b$-PNDIS, and (blue) PTQI- $b$-PNDISL. (Reprinted with permission from Ref. [75]. Copyright Royal Society of Chemistry).

\subsection{Active Nanoparticles}

Adding active nanoparticles is another strategy to adjust the $\pi-\pi$ interaction between rod blocks. Loudy et al. reported that the thin film morphologies of poly(3-hexylthiophene)$b$-poly(ethylene glycol methyl ether methacrylate) (P3HT-b-PEGMA) are changed from fibrils structure into out-of-plane cylinders after incorporating gold nanoparticles with PEG ligands. This is because the crystallization of the rod block was destroyed, and the self-assembly is driven by nanophase segregation [123]. Ye et al. found that titanium dioxide $\left(\mathrm{TiO}_{2}\right)$ nanoparticles (NPs) are preferentially confined in the P2VP domains when P3HT- $b$-P2VP mixed with nicotinic acid-modified $\mathrm{TiO}_{2} \mathrm{NPs}$. At the addition of $\mathrm{TiO}_{2} \mathrm{NPs}$ to $40 \mathrm{wt} \%$ or higher, the morphologies of lamellar and cylindrical structures are disturbed. P3HT- $b$-P2 VP $/ \mathrm{TiO}_{2}$ hybrid materials exhibit a $>30$ fold improvement in power conversion efficiency compared to the corresponding $\mathrm{P} 3 \mathrm{HT} / \mathrm{P} 2 \mathrm{VP} / \mathrm{TiO}_{2}$ polymer blend hybrid in a solar cell device [124].

\section{Summary and Outlook}

cBCPs have been considered as a novel type of materials with unique chemical structures, excellent electronic properties, and, more importantly, diverse self-assembly behaviors. In this review, we have summarized the recent progresses on the synthesis methods of different types of cBCPs and their self-assembly in solution, solid films, and thin films. We have also discussed the influences of several parameters on the morphology of cBCPs and the resulting electronic properties and device performance. Despite all the recent studies on cBCPs, this field still remains largely unexplored with many problems to be solved. From our perspective, first, a new synthetic methodology needs to be developed, especially for the synthesis of fully conjugated block copolymers. Second, compared to the "rod-coil" cBCPs, the "rod-rod" cBCPs have fully conjugated backbones and therefore are expected to have better conductivity and better electronic properties. However, feasible control over the morphology of such "rod-rod" cBCPs is still a grand challenge due to the strong inter-chain interactions and the stiffness of the conjugated backbone. Side-chain engineering is recognized as an effective solution to this problem. Thirdly, it is expected that the collaboration of theoretical studies with experimental investigation could provide more insights to guide rational designs to further improve the morphological control and performance of cBCP materials.

Author Contributions: Writing-original draft, L.-L.X. and X.Z.; writing-review and editing, K.Y. and Z.-H.G. All authors have read and agreed to the published version of the manuscript.

Funding: This research was funded by the National Natural Science Foundation of China (grant number 91856128 and 22003017) and by the Pearl River Talents Scheme (grant number 2016ZT06C322).

Conflicts of Interest: The authors declare no conflict of interest. 


\section{References}

1. Shirakawa, H.; Louis, E.J.; MacDiarmid, A.G.; Chiang, C.K.; Heeger, A.J. Synthesis of electrically conducting organic polymers: Halogen derivatives of polyacetylene, (CH)x. J. Chem. Soc. Chem. Commun. 1977, 16, 578-580. [CrossRef]

2. Tang, C.W.; VanSlyke, S.A. Organic electroluminescent diodes. Appl. Phys. Lett. 1987, 51, 913-915. [CrossRef]

3. Malliaras, G.G.; Hadziioannou, G.; Herrema, J.K.; Wildeman, J.; Wieringa, R.H.; Gill, R.E.; Lampoura, S.S. Tuning of the photoand electroluminescence in multi-block copolymers of poly[(silanylene)thiophene]s via exciton confinement. Adv. Mater. 1993, 5, 721-723. [CrossRef]

4. Park, L.S.; Han, Y.S.; Hwang, J.S.; Kim, S.D. Synthesis of conjugated polymers containing anthracene moiety and their electrooptical properties. J. Polym. Sci. Part A Polym. Chem. 2000, 38, 3173-3180. [CrossRef]

5. Romero, D.B.; Schaer, M.; Zuppiroli, L.; Cesar, B.; Widawski, G.; Francois, B. Light-emitting diodes based on copolymer organic semiconductors. Opt. Eng. 1995, 34, 1987-1992.

6. Torsi, L.; Magliulo, M.; Manoli, K.; Palazzo, G. Organic field-effect transistor sensors: A tutorial review. Chem. Soc. Rev. 2013, 42, 8612-8628. [CrossRef] [PubMed]

7. Müller, C.; Goffri, S.; Breiby, D.W.; Andreasen, J.W.; Chanzy, H.D.; Janssen, R.A.J.; Nielsen, M.M.; Radano, C.P.; Sirringhaus, H.; Smith, P.; et al. Tough, Semiconducting Polyethylene-poly(3-hexylthiophene) Diblock Copolymers. Adv. Funct. Mater. 2007, 17, 2674-2679. [CrossRef]

8. Hüttner, S.; Sommer, M.; Thelakkat, M. n-type organic field effect transistors from perylene bisimide block copolymers and homopolymers. Appl. Phys. Lett. 2008, 92, 093302. [CrossRef]

9. Cao, W.; Xue, J. Recent progress in organic photovoltaics: Device architecture and optical design. Energy Environ. Sci. 2014, 7, 2123-2144. [CrossRef]

10. Hedley, G.J.; Ruseckas, A.; Samuel, I.D.W. Light Harvesting for Organic Photovoltaics. Chem. Rev. 2017, 117, 796-837. [CrossRef]

11. Lu, Y.; Wang, J.-Y.; Pei, J. Strategies To Enhance the Conductivity of n-Type Polymer Thermoelectric Materials. Chem. Mater. 2019, 31, 6412-6423. [CrossRef]

12. Yan, X.; Xiong, M.; Li, J.-T.; Zhang, S.; Ahmad, Z.; Lu, Y.; Wang, Z.-Y.; Yao, Z.-F.; Wang, J.-Y.; Gu, X.; et al. Pyrazine-Flanked Diketopyrrolopyrrole (DPP): A New Polymer Building Block for High-Performance n-Type Organic Thermoelectrics. J. Am. Chem. Soc. 2019, 141, 20215-20221. [CrossRef]

13. Dimitrakopoulos, C.D.; Malenfant, P.R.L. Organic Thin Film Transistors for Large Area Electronics. Adv. Mater. 2002, 14, 99-117. [CrossRef]

14. Guo, C.H.; Lin, Y.H.; Witman, M.D.; Smith, K.A.; Wang, C.; Hexemer, A.; Strzalka, J.; Gomez, E.D.; Verduzco, R. Conjugated Block Copolymer Photovoltaics with near 3\% Efficiency through Microphase Separation. Nano Lett. 2013, 13, 2957-2963. [CrossRef] [PubMed]

15. Savic, R.; Luo, L.; Eisenberg, A.; Maysinger, D. Micellar nanocontainers distribute to defined cytoplasmic organelles. Science 2003, 300, 615-618. [CrossRef] [PubMed]

16. Warren, S.C.; Messina, L.C.; Slaughter, L.S.; Kamperman, M.; Zhou, Q.; Gruner, S.M.; DiSalvo, F.J.; Wiesner, U. Ordered mesoporous materials from metal nanoparticle-block copolymer self-assembly. Science 2008, 320, 1748-1752. [CrossRef]

17. Wan, Y.; Zhao, D. On the Controllable Soft-Templating Approach to Mesoporous Silicates. Chem. Rev. 2007, 107, 2821-2860. [CrossRef]

18. Riess, G. Micellization of block copolymers. Prog. Polym. Sci. 2003, 28, 1107-1170. [CrossRef]

19. Feng, H.; Lu, X.; Wang, W.; Kang, N.-G.; Mays, J.W. Block Copolymers: Synthesis, Self-Assembly, and Applications. Polymers 2017, 9, 494. [CrossRef]

20. Liu, S.S.Y.; Ludwigs, S. Electrochemical Manipulation of Aligned Block Copolymer Templates. Macromol. Rapid Commun. 2020, 41, 1900485. [CrossRef]

21. Pinto-Gómez, C.; Pérez-Murano, F.; Bausells, J.; Villanueva, L.G.; Fernández-Regúlez, M. Directed Self-Assembly of Block Copolymers for the Fabrication of Functional Devices. Polymers 2020, 12, 2432. [CrossRef] [PubMed]

22. El Jundi, A.; Buwalda, S.J.; Bakkour, Y.; Garric, X.; Nottelet, B. Double hydrophilic block copolymers self-assemblies in biomedical applications. Adv. Colloid Interface Sci. 2020, 283, 102213. [CrossRef] [PubMed]

23. Li, C.; Li, Q.; Kaneti, Y.V.; Hou, D.; Yamauchi, Y.; Mai, Y. Self-assembly of block copolymers towards mesoporous materials for energy storage and conversion systems. Chem. Soc. Rev. 2020, 49, 4681-4736. [CrossRef] [PubMed]

24. Jiao, W.; Yang, H.; Wu, Z.; Liu, J.; Zhang, W. Self-assembled block polymer aggregates in selective solution: Controllable morphology transitions and their applications in drug delivery. Expert Opin. Drug Deliv. 2020, 17, 947-961. [CrossRef] [PubMed]

25. Khandpur, A.K.; Foerster, S.; Bates, F.S.; Hamley, I.W.; Ryan, A.J.; Bras, W.; Almdal, K.; Mortensen, K. Polyisoprene-Polystyrene Diblock Copolymer Phase Diagram near the Order-Disorder Transition. Macromolecules 1995, 28, 8796-8806. [CrossRef]

26. Bates, F.S.; Fredrickson, G.H. Block Copolymers-Designer Soft Materials. Physics Today 1999, 52, 32-38. [CrossRef]

27. Chang, A.B.; Bates, F.S. The ABCs of Block Polymers. Macromolecules 2020, 53, 2765-2768. [CrossRef]

28. Mai, Y.; Eisenberg, A. Self-assembly of block copolymers. Chem. Soc. Rev. 2012, 41, 5969-5985. [CrossRef]

29. Cummins, C.; Lundy, R.; Walsh, J.; Ponsinet, V.; Fleury, G.; Morris, M. Enabling future nanomanufacturing through block copolymer self-assembly: A review. Nano Today 2020, 35, 100936. [CrossRef]

30. Xu, F.; Zhang, J.; Zhang, P.; Luan, X.; Mai, Y. “Rod-coil”" copolymers get self-assembled in solution. Mater. Chem. Front. 2019, 3, 2283-2307. [CrossRef] 
31. Ariga, K.; Nishikawa, M.; Mori, T.; Takeya, J.; Shrestha, L.K.; Hill, J.P. Self-assembly as a key player for materials nanoarchitectonics. Sci. Technol. Adv. Mater 2019, 20, 51-95. [CrossRef] [PubMed]

32. Liu, C.; Hong, C.-Y.; Pan, C.-Y. Polymerization techniques in polymerization-induced self-assembly (PISA). Polym. Chem. 2020, 11, 3673-3689. [CrossRef]

33. Varlas, S.; Lawrenson, S.B.; Arkinstall, L.A.; O’Reilly, R.K.; Foster, J.C. Self-assembled nanostructures from amphiphilic block copolymers prepared via ring-opening metathesis polymerization (ROMP). Prog. Polym. Sci. 2020, 107, 101278. [CrossRef]

34. Matsen, M.W.; Bates, F.S. Unifying Weak- and Strong-Segregation Block Copolymer Theories. Macromolecules 1996, 29 , 1091-1098. [CrossRef]

35. Mitchell, V.D.; Gann, E.; Huettner, S.; Singh, C.R.; Subbiah, J.; Thomsen, L.; McNeill, C.R.; Thelakkat, M.; Jones, D.J. Morphological and Device Evaluation of an Amphiphilic Block Copolymer for Organic Photovoltaic Applications. Macromolecules 2017, 50, 4942-4951. [CrossRef]

36. Lee, S.; Bluemle, M.J.; Bates, F.S. Discovery of a Frank-Kasper sigma phase in sphere-forming block copolymer melts. Science 2010, 330, 349-353. [CrossRef]

37. Borsali, R.; Lecommandoux, S.; Pecora, R.; Benoît, H. Scattering Properties of Rod-Coil and Once-Broken Rod Block Copolymers. Macromolecules 2001, 34, 4229-4234. [CrossRef]

38. Loo, Y.-L.; Register, R.A.; Ryan, A.J. Modes of Crystallization in Block Copolymer Microdomains: Breakout, Templated, and Confined. Macromolecules 2002, 35, 2365-2374. [CrossRef]

39. Wang, J.S.; Matyjaszewski, K. Controlled Living Radical Polymerization-Atom-Transfer Radical Polymerization in the Presence of Transition-Metal Complexes. J. Am. Chem. Soc. 1995, 117, 5614-5615. [CrossRef]

40. Chiefari, J.; Chong, Y.; Ercole, F.; Krstina, J.; Jeffery, J.; Le, T.P.; Mayadunne, R.T.; Meijs, G.F.; Moad, C.L.; Moad, G. Living Free-Radical Polymerization by Reversible Addition-Fragmentation Chain Transfer: The RAFT Process. Macromolecules 1998, 31 , 5559-5562. [CrossRef]

41. Georges, M.K.; Veregin, R.P.; Kazmaier, P.M.; Hamer, G.K. Narrow molecular weight resins by a free-radical polymerization process. Macromolecules 1993, 26, 2987-2988. [CrossRef]

42. Tung, Y.-C.; Wu, W.-C.; Chen, W.-C. Morphological Transformation and Photophysical Properties of Rod-Coil Poly[2,7-(9,9dihexylfluorene)]-block-poly(acrylic acid) in Solution. Macromol. Rapid Commun. 2006, 27, 1838-1844. [CrossRef]

43. Liu, J.; Sheina, E.; Kowalewski, T.; McCullough, R.D. Tuning the Electrical Conductivity and Self-Assembly of Regioregular Polythiophene by Block Copolymerization: Nanowire Morphologies in New Di- and Triblock Copolymers. Angew. Chem. Int. Ed. 2002, 41, 329-332. [CrossRef]

44. Lee, J.U.; Cirpan, A.; Emrick, T.; Russell, T.P.; Jo, W.H. Synthesis and photophysical property of well-defined donor-acceptor diblock copolymer based on regioregular poly(3-hexylthiophene) and fullerene. J. Mater. Chem. 2009, 19, 1483-1489. [CrossRef]

45. Brochon, C.; Sary, N.; Mezzenga, R.; Ngov, C.; Richard, F.; May, M.; Hadziioannou, G. Synthesis of poly(paraphenylene vinylene)-polystyrene-based rod-coil block copolymer by atom transfer radical polymerization: Toward a self-organized lamellar semiconducting material. J. Appl. Polym. Sci. 2008, 110, 3664-3670. [CrossRef]

46. Qu, G.; Jiang, F.; Zhang, S.; Usuda, S. A novel poly(p-phenylene vinylene)-b-poly(methyl methacrylate) rod-coil diblock copolymer. Mater. Lett. 2007, 61, 3421-3424. [CrossRef]

47. Lin, S.-T.; Tung, Y.-C.; Chen, W.-C. Synthesis, structures and multifunctional sensory properties of poly[2,7-(9,9-dihexylfluorene)]block-poly[2-(dimethylamino)ethyl methacrylate] rod-coil diblock copolymers. J. Mater. Chem. 2008, 18, 3985-3992. [CrossRef]

48. Kern, M.R.; Boyes, S.G. RAFT polymerization kinetics and polymer characterization of P3HT rod-coil block copolymers. J. Polym. Sci. Part A Polym. Chem. 2014, 52, 3575-3585. [CrossRef]

49. Stalmach, U.; de Boer, B.; Post, A.D.; van Hutten, P.F.; Hadziioannou, G. Synthesis of a Conjugated Macromolecular Initiator for Nitroxide-Mediated Free Radical Polymerization. Angew. Chem. Int. Ed. 2001, 40, 428-430. [CrossRef]

50. Dai, C.-A.; Yen, W.-C.; Lee, Y.-H.; Ho, C.-C.; Su, W.-F. Facile Synthesis of Well-Defined Block Copolymers Containing Regioregular Poly(3-hexyl thiophene) via Anionic Macroinitiation Method and Their Self-Assembly Behavior. J. Am. Chem. Soc. 2007, 129, 11036-11038. [CrossRef]

51. Park, S.-J.; Kang, S.-G.; Fryd, M.; Saven, J.G.; Park, S.-J. Highly Tunable Photoluminescent Properties of Amphiphilic Conjugated Block Copolymers. J. Am. Chem. Soc. 2010, 132, 9931-9933. [CrossRef] [PubMed]

52. Boudouris, B.W.; Frisbie, C.D.; Hillmyer, M.A. Nanoporous Poly(3-alkylthiophene) Thin Films Generated from Block Copolymer Templates. Macromolecules 2008, 41, 67-75. [CrossRef]

53. Radano, C.P.; Scherman, O.A.; Stingelin-Stutzmann, N.; Müller, C.; Breiby, D.W.; Smith, P.; Janssen, R.A.J.; Meijer, E.W. Crystalline-Crystalline Block Copolymers of Regioregular Poly(3-hexylthiophene) and Polyethylene by Ring-Opening Metathesis Polymerization. J. Am. Chem. Soc. 2005, 127, 12502-12503. [CrossRef]

54. De Cuendias, A.; Le Hellaye, M.; Lecommandoux, S.; Cloutet, E.; Cramail, H. Synthesis and self-assembly of polythiophene-based rod-coil and coil-rod-coil block copolymers. J. Mater. Chem. 2005, 15, 3264-3267. [CrossRef]

55. Li, Z.; Ono, R.J.; Wu, Z.-Q.; Bielawski, C.W. Synthesis and self-assembly of poly(3-hexylthiophene)-block-poly(acrylic acid). Chem. Commun. 2011, 47, 197-199. [CrossRef]

56. Lohwasser, R.H.; Thelakkat, M. Synthesis of Amphiphilic Rod-Coil P3HT-b-P4VP Carrying a Long Conjugated Block Using NMRP and Click Chemistry. Macromolecules 2012, 45, 3070-3077. [CrossRef] 
57. Oh, S.; Kang, S.; Cativo, M.H.M.; Yang, M.; Chung, S.H.; Kim, J.; Bouffard, J.; Hong, S.; Park, S.J. Long-Range Order Self-Assembly of Conjugated Block Copolymers at Inclined Air-Liquid Interfaces. ACS Appl. Mater. Interfaces 2020, 12, 5099-5105. [CrossRef] [PubMed]

58. Wang, H.; Wang, H.H.; Urban, V.S.; Littrell, K.C.; Thiyagarajan, P.; Yu, L. Syntheses of Amphiphilic Diblock Copolymers Containing a Conjugated Block and Their Self-Assembling Properties. J. Am. Chem. Soc. 2000, 122, 6855-6861. [CrossRef]

59. Olsen, B.D.; Segalman, R.A. Structure and Thermodynamics of Weakly Segregated Rod-Coil Block Copolymers. Macromolecules 2005, 38, 10127-10137. [CrossRef]

60. Iovu, M.C.; Sheina, E.E.; Gil, R.R.; McCullough, R.D. Experimental Evidence for the Quasi-“Living” Nature of the Grignard Metathesis Method for the Synthesis of Regioregular Poly(3-alkylthiophenes). Macromolecules 2005, 38, 8649-8656. [CrossRef]

61. Wu, P.-T.; Ren, G.; Kim, F.S.; Li, C.; Mezzenga, R.; Jenekhe, S.A. Poly(3-hexylthiophene)-b-poly(3-cyclohexylthiophene): Synthesis, microphase separation, thin film transistors, and photovoltaic applications. J. Polym. Sci. Part A Polym. Chem. 2010, 48, 614-626. [CrossRef]

62. Zhang, Y.; Tajima, K.; Hashimoto, K. Nanostructure Formation in Poly(3-hexylthiophene-block-3-(2-ethylhexyl)thiophene)s. Macromolecules 2009, 42, 7008-7015. [CrossRef]

63. He, M.; Zhao, L.; Wang, J.; Han, W.; Yang, Y.; Qiu, F.; Lin, Z. Self-Assembly of All-Conjugated Poly(3-alkylthiophene) Diblock Copolymer Nanostructures from Mixed Selective Solvents. ACS Nano 2010, 4, 3241-3247. [CrossRef] [PubMed]

64. He, M.; Han, W.; Ge, J.; Yu, W.; Yang, Y.; Qiu, F.; Lin, Z. Annealing effects on the photovoltaic performance of all-conjugated poly(3-alkylthiophene) diblock copolymer-based bulk heterojunction solar cells. Nanoscale 2011, 3, 3159-3163. [CrossRef]

65. Lee, K.S.; Kim, P.; Lee, J.; Choi, C.; Seo, Y.; Park, S.Y.; Kim, K.; Park, C.; Cho, K.; Moon, H.C.; et al. End-on Chain Orientation of Poly(3-alkylthiophene)s on a Substrate by Microphase Separation of Lamellar Forming Amphiphilic Diblock Copolymer. Macromolecules 2019, 52, 6734-6740. [CrossRef]

66. Bridges, C.R.; Yan, H.; Pollit, A.A.; Seferos, D.S. Controlled Synthesis of Fully $\pi$-Conjugated Donor-Acceptor Block Copolymers Using a Ni(II) Diimine Catalyst. ACS Macro Lett. 2014, 3, 671-674. [CrossRef]

67. Loewe, R.S.; Khersonsky, S.M.; McCullough, R.D. A Simple Method to Prepare Head-to-Tail Coupled, Regioregular Poly(3alkylthiophenes) Using Grignard Metathesis. Adv. Mater. 1999, 11, 250-253. [CrossRef]

68. Stefan, M.C.; Bhatt, M.P.; Sista, P.; Magurudeniya, H.D. Grignard metathesis (GRIM) polymerization for the synthesis of conjugated block copolymers containing regioregular poly(3-hexylthiophene). Polym. Chem. 2012, 3, 1693-1701. [CrossRef]

69. Park, S.H.; Kim, Y.; Kwon, N.Y.; Lee, Y.W.; Woo, H.Y.; Chae, W.S.; Park, S.; Cho, M.J.; Choi, D.H. Significantly Improved Morphology and Efficiency of Nonhalogenated Solvent-Processed Solar Cells Derived from a Conjugated Donor-Acceptor Block Copolymer. Adv. Sci. 2020, 7, 1902470. [CrossRef]

70. Rahmanudin, A.; Yao, L.; Sekar, A.; Cho, H.-H.; Liu, Y.; Lhermitte, C.R.; Sivula, K. Fully Conjugated Donor-Acceptor Block Copolymers for Organic Photovoltaics via Heck-Mizoroki Coupling. ACS Macro Lett. 2019, 8, 134-139. [CrossRef]

71. Lin, Y.-H.; Smith, K.A.; Kempf, C.N.; Verduzco, R. Synthesis and crystallinity of all-conjugated poly(3-hexylthiophene) block copolymers. Polym. Chem. 2013, 4, 229-232. [CrossRef]

72. Ku, S.Y.; Brady, M.A.; Treat, N.D.; Cochran, J.E.; Robb, M.J.; Kramer, E.J.; Chabinyc, M.L.; Hawker, C.J. A modular strategy for fully conjugated donor-acceptor block copolymers. J. Am. Chem. Soc. 2012, 134, 16040-16046. [CrossRef] [PubMed]

73. Lee, J.H.; Park, C.G.; Kim, A.; Kim, H.J.; Kim, Y.; Park, S.; Cho, M.J.; Choi, D.H. High-Performance Polymer Solar Cell with Single Active Material of Fully Conjugated Block Copolymer Composed of Wide-Band gap Donor and Narrow-Band gap Acceptor Blocks. ACS Appl. Mater. Interfaces 2018, 10, 18974-18983. [CrossRef] [PubMed]

74. Park, C.G.; Park, S.H.; Kim, Y.; Nguyen, T.L.; Woo, H.Y.; Kang, H.; Yoon, H.J.; Park, S.; Cho, M.J.; Choi, D.H. Facile one-pot polymerization of a fully conjugated donor-acceptor block copolymer and its application in efficient single component polymer solar cells. J. Mater. Chem. A 2019, 7, 21280-21289. [CrossRef]

75. Lee, D.H.; Lee, J.H.; Kim, H.J.; Choi, S.; Park, G.E.; Cho, M.J.; Choi, D.H. (D)n-o-(A)m type partially conjugated block copolymer and its performance in single-component polymer solar cells. J. Mater. Chem. A 2017, 5, 9745-9751. [CrossRef]

76. Chevrier, M.; Lopez, G.; Zajaczkowski, W.; Kesters, J.; Lenaerts, R.; Surin, M.; De Winter, J.; Richeter, S.; Pisula, W.; Mehdi, A.; et al. Synthesis and properties of a P3HT-based ABA triblock copolymer containing a perfluoropolyether central segment. Synth. Met. 2019, 252, 127-134. [CrossRef]

77. Verheyen, L.; Timmermans, B.; Koeckelberghs, G. Influence of the Sequence in Conjugated Triblock Copolymers on Their Aggregation Behavior. Macromolecules 2018, 51, 6421-6429. [CrossRef]

78. Lee, S.; Cheng, L.-C.; Yager, K.G.; Mumtaz, M.; Aissou, K.; Ross, C.A. In Situ Study of ABC Triblock Terpolymer Self-Assembly under Solvent Vapor Annealing. Macromolecules 2019, 52, 1853-1863. [CrossRef]

79. Kalow, J.A.; Swager, T.M. Synthesis of Miktoarm Branched Conjugated Copolymers by ROMPing In and Out. ACS Macro Lett. 2015, 4, 1229-1233. [CrossRef]

80. Park, J.; Moon, H.C.; Choi, C.; Kim, J.K. Synthesis and Characterization of [Poly(3-dodecylthiophene)]2Poly(methyl methacrylate) Miktoarm Star Copolymer. Macromolecules 2015, 48, 3523-3530. [CrossRef]

81. Park, J.; Choi, C.; Hyun, S.; Moon, H.C.; Vincent Joseph, K.L.; Kim, J.K. Microphase Separation of P3HT-Containing Miktoarm Star Copolymers. Macromolecules 2016, 49, 616-623. [CrossRef] 
82. Park, J.; Moon, H.C.; Kim, J.K. Facile synthesis for well-defined A2B miktoarm star copolymer of poly(3-hexylthiophene) and poly (methyl methacrylate) by the combination of anionic polymerization and click reaction. J. Polym. Sci. Part A Polym. Chem. 2013, 51, 2225-2232. [CrossRef]

83. Higashihara, T.; Ito, S.; Fukuta, S.; Miyane, S.; Ochiai, Y.; Ishizone, T.; Ueda, M.; Hirao, A. Synthesis and Characterization of Multicomponent ABC- and ABCD-Type Miktoarm Star-Branched Polymers Containing a Poly(3-hexylthiophene) Segment. ACS Macro Lett. 2016, 5, 631-635. [CrossRef]

84. Ahn, S.-K.; Carrillo, J.-M.Y.; Keum, J.K.; Chen, J.; Uhrig, D.; Lokitz, B.S.; Sumpter, B.G.; Michael Kilbey, S. Nanoporous poly(3hexylthiophene) thin film structures from self-organization of a tunable molecular bottlebrush scaffold. Nanoscale 2017, 9 , 7071-7080. [CrossRef]

85. Ahn, S.-k.; Nam, J.; Zhu, J.; Lee, E.; Michael Kilbey, S. Solution self-assembly of poly(3-hexylthiophene)-poly(lactide) brush copolymers: Impact of side chain arrangement. Polym. Chem. 2018, 9, 3279-3286. [CrossRef]

86. Gao, Y.; Zhang, X.; Yang, M.; Zhang, X.; Wang, W.; Wegner, G.; Burger, C. Synthesis and Cylinder Microdomain Structures of Hybrid Block Copolymers of $\pi$-Conjugated and Dendritic Poly(phenylazomethine)s and Flexible and Linear PEO. Macromolecules 2007, 40, 2606-2612. [CrossRef]

87. Yang, W.Y.; Lee, E.; Lee, M. Tubular organization with coiled ribbon from amphiphilic rigid-flexible macrocycle. J. Am. Chem. Soc. 2006, 128, 3484-3485. [CrossRef]

88. Chen, J.T.; Thomas, E.L.; Ober, C.K.; Mao, G. Self-Assembled Smectic Phases in Rod-Coil Block Copolymers. Science 1996, 273, 343-346. [CrossRef]

89. Radzilowski, L.H.; Carragher, B.O.; Stupp, S.I. Three-Dimensional Self-Assembly of Rodcoil Copolymer Nanostructures. Macromolecules 1997, 30, 2110-2119. [CrossRef]

90. Tenneti, K.K.; Chen, X.; Li, C.Y.; Tu, Y.; Wan, X.; Zhou, Q.F.; Sics, I.; Hsiao, B.S. Perforated layer structures in liquid crystalline rod-coil block copolymers. J. Am. Chem. Soc. 2005, 127, 15481-15490. [CrossRef]

91. Ryu, J.-H.; Oh, N.-K.; Zin, W.-C.; Lee, M. Self-assembly of rod-coil molecules into molecular length-dependent organization. J. Am. Chem. Soc. 2004, 126, 3551-3558. [CrossRef] [PubMed]

92. Sary, N.; Rubatat, L.; Brochon, C.; Hadziioannou, G.; Ruokolainen, J.; Mezzenga, R. Self-Assembly of Poly(diethylhexyloxy-pphenylenevinylene)-b- poly(4-vinylpyridine) Rod-Coil Block Copolymer Systems. Macromolecules 2007, 40, 6990-6997. [CrossRef]

93. Reenders, M.; ten Brinke, G. Compositional and Orientational Ordering in Rod-Coil Diblock Copolymer Melts. Macromolecules 2002, 35, 3266-3280. [CrossRef]

94. Scherf, U.; Adamczyk, S.; Gutacker, A.; Koenen, N. All-conjugated, rod-rod block copolymers-generation and self-assembly properties. Macromol. Rapid Commun. 2009, 30, 1059-1065. [CrossRef] [PubMed]

95. Lim, Y.-B.; Moon, K.-S.; Lee, M. Rod-coil block molecules: Their aqueous self-assembly and biomaterials applications. J. Mater. Chem. 2008, 18, 2909-2918. [CrossRef]

96. Kim, B.S.; Yang, W.Y.; Ryu, J.H.; Yoo, Y.S.; Lee, M. Carbohydrate-coated nanocapsules from amphiphilic rod-coil molecule: Binding to bacterial type 1 pili. Chem. Commun. 2005, 15, 2035-2037. [CrossRef]

97. Kim, B.-S.; Hong, D.-J.; Bae, J.; Lee, M. Controlled Self-Assembly of Carbohydrate Conjugate Rod-Coil Amphiphiles for Supramolecular Multivalent Ligands. J. Am. Chem. Soc. 2005, 127, 16333-16337. [CrossRef]

98. Jenekhe, S.A.; Chen, X.L. Self-Assembled Aggregates of Rod-Coil Block Copolymers and Their Solubilization and Encapsulation of Fullerenes. Science 1998, 279, 1903. [CrossRef]

99. Segalman, R.A.; McCulloch, B.; Kirmayer, S.; Urban, J.J. Block Copolymers for Organic Optoelectronics. Macromolecules 2009, 42, 9205-9216. [CrossRef]

100. Roncali, J.; Grosu, I. The Dawn of Single Material Organic Solar Cells. Adv. Sci. 2019, 6, 1801026. [CrossRef]

101. Yassar, A.; Miozzo, L.; Gironda, R.; Horowitz, G. Rod-coil and all-conjugated block copolymers for photovoltaic applications. Prog. Polym. Sci. 2013, 38, 791-844. [CrossRef]

102. Lee, Y.; Gomez, E.D. Challenges and Opportunities in the Development of Conjugated Block Copolymers for Photovoltaics. Macromolecules 2015, 48, 7385-7395. [CrossRef]

103. Kim, H.-C.; Park, S.-M.; Hinsberg, W.D. Block Copolymer Based Nanostructures: Materials, Processes, and Applications to Electronics. Chem. Rev. 2010, 110, 146-177. [CrossRef]

104. Botiz, I.; Darling, S.B. Optoelectronics using block copolymers. Mater. Today 2010, 13, 42-51. [CrossRef]

105. Sirringhaus, H.; Brown, P.J.; Friend, R.H.; Nielsen, M.M.; Bechgaard, K.; Langeveld-Voss, B.M.W.; Spiering, A.J.H.; Janssen, R.A.J.; Meijer, E.W.; Herwig, P.; et al. Two-dimensional charge transport in self-organized, high-mobility conjugated polymers. Nature 1999, 401, 685-688. [CrossRef]

106. Han, J.; Kim, J.-S.; Shin, J.M.; Yun, H.; Kim, Y.; Park, H.; Kim, B.J. Rapid solvo-microwave annealing for optimizing ordered nanostructures and crystallization of regioregular polythiophene-based block copolymers. Polym. Chem. 2019, 10, 4962-4972. [CrossRef]

107. Wu, P.-T.; Ren, G.; Li, C.; Mezzenga, R.; Jenekhe, S.A. Crystalline Diblock Conjugated Copolymers: Synthesis, Self-Assembly, and Microphase Separation of Poly(3-butylthiophene)-b-poly(3-octylthiophene). Macromolecules 2009, 42, 2317-2320. [CrossRef]

108. Hollinger, J.; Jahnke, A.A.; Coombs, N.; Seferos, D.S. Controlling Phase Separation and Optical Properties in Conjugated Polymers through Selenophene-Thiophene Copolymerization. J. Am. Chem. Soc. 2010, 132, 8546-8547. [CrossRef] 
109. Ren, G.; Wu, P.-T.; Jenekhe, S.A. Enhanced Performance of Bulk Heterojunction Solar Cells Using Block Copoly(3-alkylthiophene)s. Chem. Mater. 2010, 22, 2020-2026. [CrossRef]

110. Ge, J.; He, M.; Qiu, F.; Yang, Y. Synthesis, Cocrystallization, and Microphase Separation of All-Conjugated Diblock Copoly(3alkylthiophene)s. Macromolecules 2010, 43, 6422-6428. [CrossRef]

111. Yang, H.; Zhang, R.; Wang, L.; Zhang, J.; Yu, X.; Liu, J.; Xing, R.; Geng, Y.; Han, Y. Face-On and Edge-On Orientation Transition and Self-Epitaxial Crystallization of All-Conjugated Diblock Copolymer. Macromolecules 2015, 48, 7557-7566. [CrossRef]

112. Stalmach, U.; de Boer, B.; Videlot, C.; van Hutten, P.F.; Hadziioannou, G. Semiconducting Diblock Copolymers Synthesized by Means of Controlled Radical Polymerization Techniques. J. Am. Chem. Soc. 2000, 122, 5464-5472. [CrossRef]

113. Lee, Y.-H.; Yen, W.-C.; Su, W.-F.; Dai, C.-A. Self-assembly and phase transformations of $\pi$-conjugated block copolymers that bend and twist: From rigid-rod nanowires to highly curvaceous gyroids. Soft Matter 2011, 7, 10429-10442. [CrossRef]

114. Kynaston, E.L.; Winchell, K.J.; Yee, P.Y.; Manion, J.G.; Hendsbee, A.D.; Li, Y.; Huettner, S.; Tolbert, S.H.; Seferos, D.S. Poly(3alkylthiophene)-block-poly(3-alkylselenophene)s: Conjugated Diblock Co-polymers with Atypical Self-Assembly Behavior. ACS Appl. Mater. Interfaces 2019, 11, 7174-7183. [CrossRef] [PubMed]

115. Lei, T.; Wang, J.-Y.; Pei, J. Roles of Flexible Chains in Organic Semiconducting Materials. Chem. Mater. 2014, 26, 594-603. [CrossRef]

116. Mei, J.; Bao, Z. Side Chain Engineering in Solution-Processable Conjugated Polymers. Chem. Mater. 2014, 26, 604-615. [CrossRef]

117. Guo, Z.-H.; Ai, N.; McBroom, C.R.; Yuan, T.; Lin, Y.-H.; Roders, M.; Zhu, C.; Ayzner, A.L.; Pei, J.; Fang, L. A side-chain engineering approach to solvent-resistant semiconducting polymer thin films. Polym. Chem. 2016, 7, 648-655. [CrossRef]

118. Lin, S.-H.; Wu, S.-J.; Ho, C.-C.; Su, W.-F. Rational Design of Versatile Self-Assembly Morphology of Rod-Coil Block Copolymer. Macromolecules 2013, 46, 2725-2732. [CrossRef]

119. Lombeck, F.; Komber, H.; Sepe, A.; Friend, R.H.; Sommer, M. Enhancing Phase Separation and Photovoltaic Performance of All-Conjugated Donor-Acceptor Block Copolymers with Semifluorinated Alkyl Side Chains. Macromolecules 2015, 48, 7851-7860. [CrossRef]

120. Kim, J.-S.; Kim, Y.; Kim, H.-J.; Kim, H.J.; Yang, H.; Jung, Y.S.; Stein, G.E.; Kim, B.J. Regioregularity-Driven Morphological Transition of Poly(3-hexylthiophene)-Based Block Copolymers. Macromolecules 2017, 50, 1902-1908. [CrossRef]

121. Kim, J.-S.; Han, J.; Kim, Y.; Park, H.; Coote, J.P.; Stein, G.E.; Kim, B.J. Domain Structures of Poly(3-dodecylthiophene)-Based Block Copolymers Depend on Regioregularity. Macromolecules 2018, 51, 4077-4084. [CrossRef]

122. Coote, J.P.; Kim, J.-S.; Lee, B.; Han, J.; Kim, B.J.; Stein, G.E. Crystallization Modes of Poly(3-dodecylthiophene)-Based Block Copolymers Depend on Regioregularity and Morphology. Macromolecules 2018, 51, 9276-9283. [CrossRef]

123. Mawele Loudy, C.; Allouche, J.; Bousquet, A.; Courreges, C.; Martinez, H.; Billon, L. Core@Corona Functional NanoparticleDriven Rod-Coil Diblock Copolymer Self-Assembly. Langmuir 2019, 35, 16925-16934. [CrossRef] [PubMed]

124. Yen, W.-C.; Lee, Y.-H.; Lin, J.-F.; Dai, C.-A.; Jeng, U.S.; Su, W.-F. Effect of TiO2 Nanoparticles on Self-Assembly Behaviors and Optical and Photovoltaic Properties of the P3HT-b-P2VP Block Copolymer. Langmuir 2011, 27, 109-115. [CrossRef] 